\title{
RADAR BACKSCATTER MEASUREMENTS FROM ARCTIC SEA ICE DURING THE \\ FALL FREEZE-UP
}

\author{
S. Beaven, S. P. Gogineni, M. Shanableh
}

Radar Systems and Remote Sensing Laboratory, Electrical and Computer Engineering, University of Kansas, 2291 Irving Hill Road, Lawrence, Kansas 66045-2969 TEL 913/8644835 FAX: 913/864-7789 * OMNET: KANSAS.U.RSL

\author{
A. Gow, W. Tucker
}

U. S. Army Cold Regions Research \& Engineering Laboratory

72 Lyme Road, Hanover NH 03755-1290 TEL 603/646-4256

$$
\text { K. Jezek }
$$

Byrd Polar Research Center, 108 Scott Hall, The Ohio State University 1090 Carmack Road, Columbus OH 43210-1002 TEL 614/292-7973

\section{February 1993}

RSL Technical Report 8241-1

Sponsored by:

NASA Headquarters, Washington DC 20546

Grant NAGW-1984; D-10847

RSL Technical Report 8243-1

Sponsored by:

Office of Naval Research, Arlington VA 22217-5000

Grant N00014-89-J-1456 


\section{Table of Contents}

1. International Arctic Ocean Expedition 1991

(IAOE'91) Overview

2. Sensor Description

3. IAOE'91 Experiment Description

4. Signal Processing, Calibration, and Noise Reduction 15

4.1 FM-CW radar signal processing 15

4.2 Coherent noise reduction 16

4.3 Coherent noise reduction results 18

4.4 Radar calibration 22

5. In-situ Geophysical Information 24

5.1 In situ snow data 24

5.2 In situ sea ice data 25

6. Sea Ice Backscatter Measurement Results 29

6.1 Sea ice station measurements 29

6.2 Transit data results 47

6.2.1 First-/Second-year and multiyear transit data ........ 48

6.2.2 Young sea ice types .............................................. 50

7. Comparison to Scattering Theory 55

7.1 Rayleigh model for volume scattering from a snow layer during IAOE'91 55

7.2 Effect of wet snow on backscatter

8. Summary of IAOE'91 Results 60

9. References 63

10. Appendix: Timetable of major events 64 


\section{International Arctic Ocean Expedition 1991 (IAOE'91) Overview}

Radar backscatter measurements from sea ice during the fall freeze-up were performed from aboard the United States Coast Guard Icebreaker Polar Star as a part of the International Arctic Ocean Expedition (IAOE'91) in August-September, 1991. The US portion of the experiment took place on board the Polar Star and has been referred to TRAPOLEX'91 (Transpolar expedition) by some investigators. Before prematurely aborting its mission because of mechanical failure of her port shaft the Polar Star reached $84^{\circ} 57^{\prime} \mathrm{N}$. latitude at $35^{\circ} \mathrm{E}$. longitude. The ship was in the ice (> 50\% coverage) from 14 August until 3 September and was operational for all but 6 days due to two instances of mechanical problems with the port shaft. The second was fatal to the ship's participation in the expedition.

During the expedition radar backscatter was measured at C-band under a variety of conditions. These included measurements from young ice types as well as from multiyear and first-/second-year sea ice during the fall freeze-up. The sea ice types were determined by measurement of the ice properties at several of the stations and by visual inspection on others. Radar backscatter measurements were performed over a large portion of the ship's transit into the Arctic ice pack. These were accompanied by in situ sea ice property characterization by the US Army Cold Regions Research and Engineering Laboratory (CRREL) at several stations and, when snow was present, its properties were documented by The Microwave Group, Ottawa River (MWG). 
The C-band backscatter for multiyear and first-/second-year sea ice increased dramatically as temperatures dropped during the onset of the freeze-up. This dramatic increase has been observed before from spaceborne scatterometers at Ku band [Drinkwater, et al., 1991] but not during in situ experiments where the physical appearance of the ice and snow could be observed closely. Also, the measurements from the ship-borne scatterometer can exclude or include the effect of melt ponds on the backscatter. This is accomplished by using information from in situ photography in the analysis of the data. Previous scatterometers from space had a large footprint and the effect of melt pond re-freezing was proposed as one of the possible mechanisms for the increase in the backscatter. The measurements presented here were usually made without the influence of melt ponds in the radar footprint. In cases where there were melt ponds in the study area, the measurements at these angles were thrown out, with the aid of photographs made at every measurement site. The measured increase in backscatter is then caused by factors other than the re-freezing of the melt ponds. Possibilities include the increase in volume scatter from an increase in snow cover or the reduction of penetration into the ice due to high liquid water content in the upper layers of the sea ice or snow. These possibilities are addressed in section 7.

Early sea ice growth is a major factor in the modulation of heat flux between the ocean and the Arctic air. The young sea ice types generally have lower backscatter returns than multiyear or first-year sea ice [Gray, et al., 1982], [Onstott and Delker, 1979]. Some of the young ice had very low backscatter measured during IAOE'91. Dark nilas for example had a measured $\sigma^{\circ}$ of -30 to $-35 \mathrm{~dB}$ at $\mathrm{VV}$ polarization and $35^{\circ}$ incidence angle. This is important when considering the capability of SAR for observing these young ice types from space. The current sensor in space used for monitoring the Arctic is the ERS-1 SAR, which operates at C band. This system is capable of observing 
backscatter coefficients as low as $-27 \mathrm{~dB}$ in the Arctic at incidence angles ranging from $19^{\circ}$ to $27^{\circ}$. These are the important facts to consider when observing the backscatter characteristics of young saline ice.

To obtain high quality radar backscatter measurements from the systems used for the experiment a coherent noise removal technique was applied to the data. Ideally, to remove this type of noise, a "sky" measurement is performed with the radar system. That is, the radar antenna is pointed toward the sky so that there is virtually no target. This will provide a measure of the noise induced by the radar system itself, including the effects of the antenna. The technique used in this study is similar to subtracting out the noise measured from taking "sky" measurements, but uses returns from various angles of incidence to obtain an estimate of the coherent noise. This noise reduction technique improved the signal-to-noise ratio (SNR) of the measurements by up to 20$30 \mathrm{~dB}$. The success of this technique was essential in obtaining the backscatter measurements obtained during IAOE' 91. 


\section{Sensor Description}

A dual-frequency, frequency-modulated continuous-wave (FM-CW) radar system was used to perform the backscatter measurements taken during IAOE'91. The

scatterometer is actually a combination of two identical radar systems that utilized a dual-feed parabolic reflector antenna, built at The University of Kansas. The system is

divided into a $\mathrm{C}$-band section and an $\mathrm{X}$-band section. A block diagram describing these systems is shown in figure 2.1 .

The YIG-tuned oscillator is used to generate a CW waveform, which is modulated by applying a low frequency waveform to its tuning port. A portion of the waveform is coupled into the quadrature mixer. The other portion of the RF signal is then fed to the antennas via a series of switches and circulators. The switches are controlled by computer to switch between the different transmit and receive polarization combinations. The measurement of the radar return from all four linear polarization combinations (VV, $\mathrm{HH}, \mathrm{VH}, \mathrm{HV})$ as well as a delay line measurement are possible with this scheme. Both the in-phase and quadrature (I and Q) signals are obtained by mixing the returned signal with the coupled portion of the transmitted signal with the quadrature mixer. The I and Q signals are fed into the IF section of the radar system, digitized, then stored onto disk. The IF section is also used to generate the triangle waveform, which drives the YIG-tuned oscillator and provides the triangular FM modulation. The system operating parameters are described in Table 2.1. 


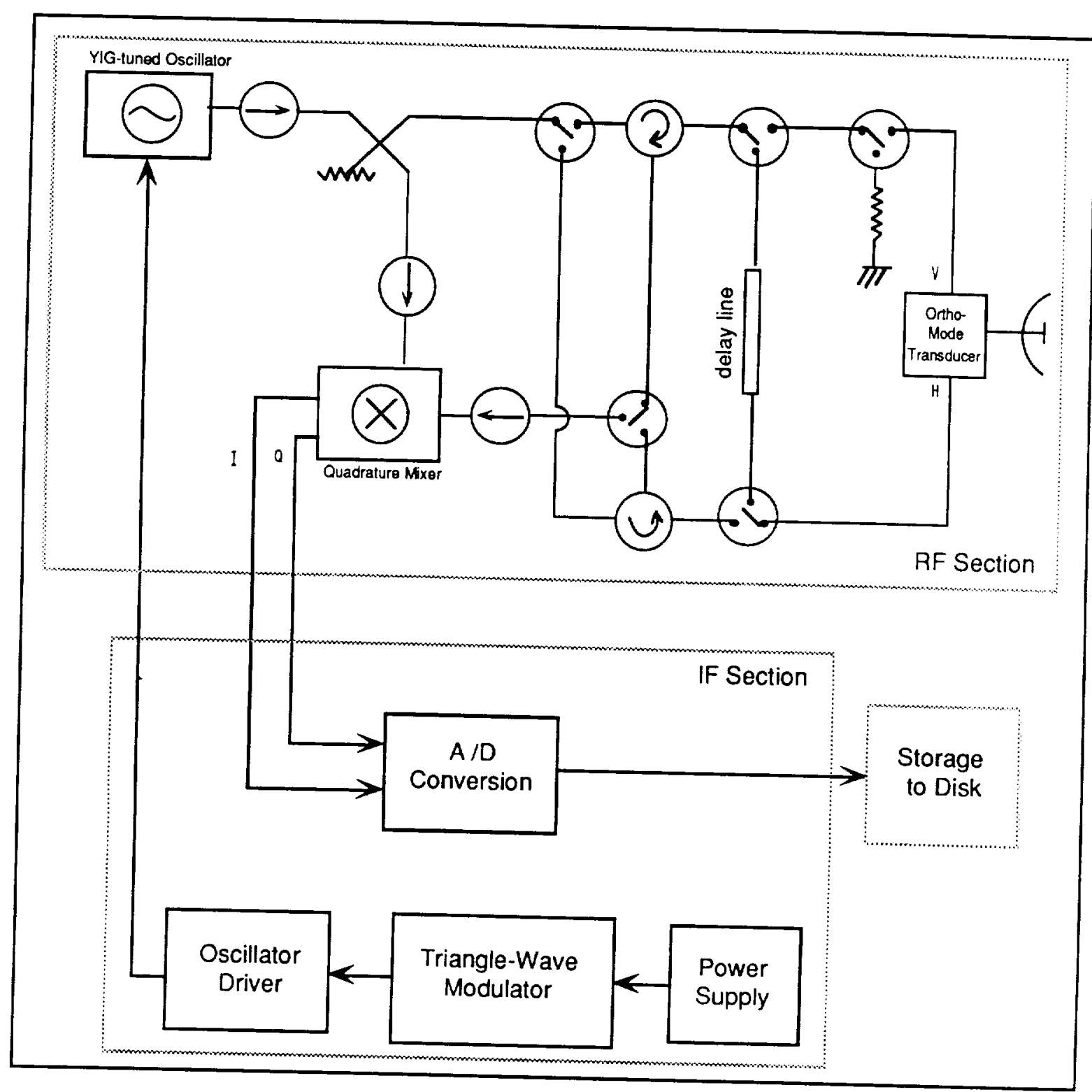

Figure 2.1 FM-CW Radar System

Both the $\mathrm{C}$-band and $\mathrm{X}$-band RF sections are housed in a single assembly, separate from the rest of the radar system. This facilitates the mounting of this portion of the system as close to the antenna as possible. This reduces the amount of loss through the coaxial cables between the RF box and the antenna feeds. Both IF sections are also housed in their own box. The RF and IF boxes were mounted outdoors along with the 
antenna mount structure. Both portions of the system were operated simultaneously using a Zenith 386 computer system to provide the control over the switching and to store the data.

\begin{tabular}{|ccc|}
\hline \multicolumn{3}{|c|}{ Table 2.1 FM-CW Radar Scatterometer Parameters } \\
\hline \hline & $\underline{\text { C band }}$ & $\underline{\text { X band }}$ \\
Center Frequency. (GHz) & 6.2 & 11.3 \\
RF Bandwidth (MHz) & 300 & 300 \\
Free-space Resolution (cm) & 50 & 50 \\
Antenna Beamwidth & $6^{\circ}$ & $3^{\circ}$ \\
Footprint in cm (23m range) & $48 \times 48$ & $24 \times 24$ \\
Transmit power (mW) & 10 & 10 \\
\hline
\end{tabular}

The antenna consisted of a single parabolic reflector with two conical horn feeds, one for the $\mathrm{C}$-band portion and the other for the $\mathrm{X}$-band portion of the system. The system as mounted for the IAOE'91 experiment is shown in photographs 2.1 and 2.2. Photograph 2.1 shows the antenna mount structure, with the RF and IF boxes mounted. Photograph 2.2 shows the computer control center, mounted within the bridge of the USCGC Polar Star. From here the ice conditions could be monitored while data were being acquired with the system. This is vital in any field study of sea ice backscatter measurements.

Due to hardware problems with the circulators in RF portion of the X-band system, only the cross-polarized returns were able to be measured. All four linear polarization 
measurements were successfully performed with the C-band system. The C-band measurements are vital in the study of Arctic sea ice backscatter because both the ERS-1 SAR and the Canadian SAR, RADARSAT (scheduled for 1995 launch), operate at C band.

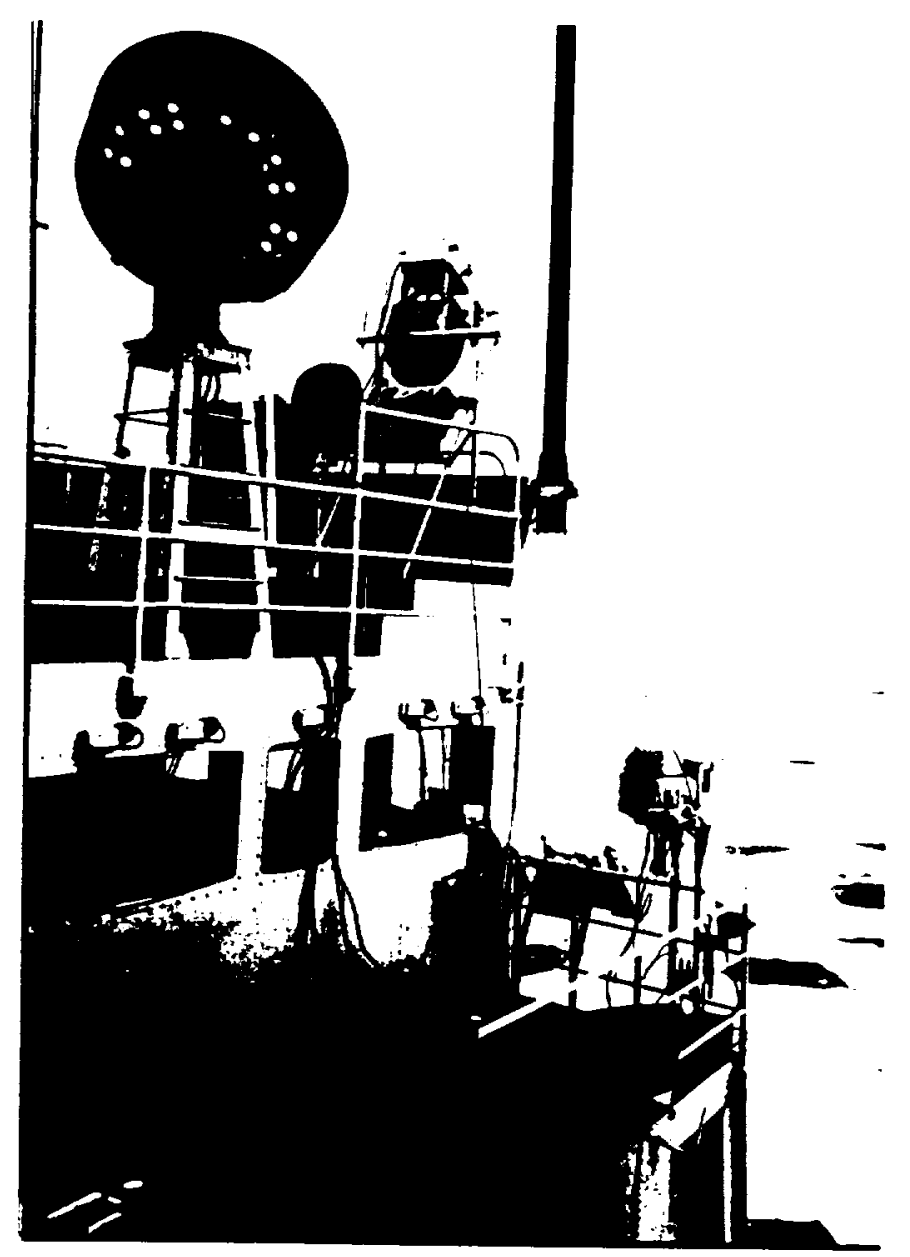

Photograph 2.1 FM-CW radar system as mounted for IAOE'91 aboard the Polar Star. The radar system is mounted along the upper rail of the bridge just to the right of the large satellite receiver antenna. The RF box is mounted above the antennas and the IF box (in blue) is on the lower part of the antenna. This structure was mounted on the flying bridge, just above the main bridge, where the radar was controlled and operated. The microwave radiometer, operated by MWG, is also shown here on the lower rail. 


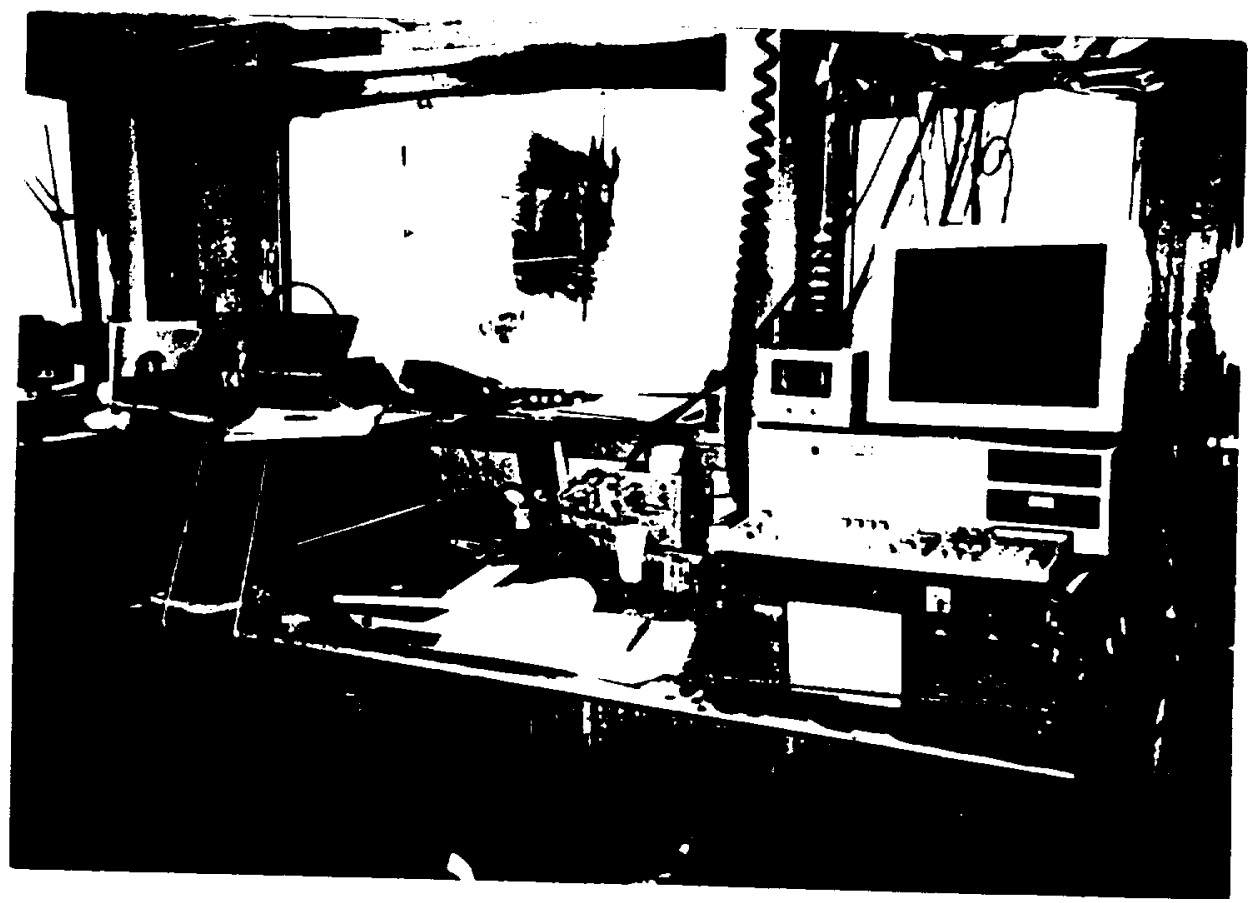

Photograph 2.2 Data acquisition and control for the FM-CW radar system.

This portion of the radar system was operated from the main bridge of the Polar Star during IAOE'91. 


\section{IAOE'91 Experiment Description}

Radar backscatter measurements were performed with a dual-frequency FM-CW radar scatterometer built by The University of Kansas Radar Systems and Remote Sensing Laboratory (RSL). Measurements were made concurrently with radiometer measurements by MWG. After overcoming some cabling problems with the system the RSL scatterometers were operational on 22 August until their required take down on 2 September as the ship was nearing the ice edge.

Measurements were made as the ship was transiting at fixed angles of $50^{\circ}, 30^{\circ}$ and $35^{\circ}$, with a majority of the transit data collected at $35^{\circ}$ angle of incidence. The radar was also operated at angles of incidence from $15^{\circ}$ to $65^{\circ}$ at a number of fixed ice stations. At some of these ice stations coincident ice and snow characterization measurements were performed. In most cases, for both fixed mode and transit mode, coincident passive microwave data were obtained by MWG. Table 3.1 describes the data set collected during IAOE'91 using abbreviations defined below:

$S, T$ - denotes whether data is in transit $(T)$ or at an ice station $(S)$ MY - multiyear sea ice, FY - first-year sea ice, 2Y - "second-year" sea ice

$\mathrm{Ni}$ - nilas ice, $\mathrm{OW}$ - open water, $\mathrm{Gr}$ - "grease" ice, $\mathrm{Br}$ - brash ice

$\mathrm{Pk}$ - "pancake "ice", Fr - frazil ice, Sl - slush ice

Dt - "dirty" ice, containing noticeably large amounts of sediment MWG - coincident passive microwave data and snow measurements by MWG CRREL - Ice characterization performed by USA CRREL rough - Surface roughness measurements performed by RSL. 


\begin{tabular}{|c|c|c|c|c|c|}
\hline Date & $\begin{array}{l}\text { Time } \\
\text { (GMT) }\end{array}$ & $\mathrm{S} / \mathrm{T}$ & Ice Types & $\begin{array}{l}\text { Coincident } \\
\text { Data }\end{array}$ & Angles \\
\hline \multirow[t]{3}{*}{22 Aug. } & 07:50 & S & FY & MWG, & $15-65$ \\
\hline & & & & CRREL & \\
\hline & $10: 44$ & $S$ & FY & & \\
\hline \multirow[t]{2}{*}{23 Aug } & $12: 25$ & $S$ & FY & MWG, & $15-65$ \\
\hline & & & & CRREL & \\
\hline \multirow[t]{3}{*}{24 Aug } & $14: 56$ & S & MY & MWG, & $35-70$ \\
\hline & & & & CRREL & \\
\hline & $13: 15$ & $\mathrm{~T}$ & MY, Dt & MWG & 55 \\
\hline \multirow[t]{3}{*}{ 25.Aug } & $12: 45$ & $\mathrm{~T}$ & $M Y, 2 Y$ & MWG & 35 \\
\hline & $16: 15$ & $\mathrm{~T}$ & MY, Ni & MWG & 35,45 \\
\hline & $18: 15$ & $S$ & MY & MWG & $15-65$ \\
\hline \multirow[t]{3}{*}{27 Aug } & $11: 58$ & $S$ & MY & MWG, & $15-65$ \\
\hline & & & & CRREL & \\
\hline & $14: 32$ & $S$ & MY & & \\
\hline \multirow[t]{3}{*}{28 Aug } & $14: 00$ & $\mathrm{~T}$ & $M Y, 2 Y$ & MWG & 35 \\
\hline & $17: 30$ & $\mathrm{~T}$ & & & \\
\hline & $22: 10$ & $\mathrm{~T}$ & MY & & 30 \\
\hline 29 Aug & $08: 55$ & $S$ & MY & $\begin{array}{l}\text { MWG, } \\
\text { rough }\end{array}$ & $15-65$ \\
\hline
\end{tabular}




\begin{tabular}{|c|c|c|c|c|c|}
\hline & $14: 00$ & $S$ & MY & & $15-65$ \\
\hline & $17: 20$ & $\mathrm{~T}$ & $\mathrm{FY}, \mathrm{Br}$ & & 30,35 \\
\hline & $18: 00$ & $\mathrm{~T}$ & MY, FY & & 35 \\
\hline & $19: 40$ & $\mathrm{~T}$ & MY & & $15-65$ \\
\hline \multirow[t]{4}{*}{30 Aug } & $13: 00$ & $\mathrm{~T}$ & $\mathrm{MY}, \mathrm{Ni}$ & MWG & 35 \\
\hline & & $\mathrm{T}$ & MY, FY & & $25,35,45$ \\
\hline & $16: 00$ & $\mathrm{~T}$ & $\mathrm{Fr}, \mathrm{Gr} / \mathrm{Ni}$ & & 35 \\
\hline & $18: 30$ & $S$ & FY, MY & rough & $15-55$ \\
\hline 31 Aug & $13: 20$ & $S$ & MY & MWG & $15-65$ \\
\hline \multirow[t]{4}{*}{$1 \mathrm{Sept}$} & $00: 25$ & $S$ & MY & & $15-65$ \\
\hline & & $\mathrm{T}$ & $\mathrm{MY}, \mathrm{Ni}$ & & 35 \\
\hline & $15: 20$ & $S$ & MY & MWG & $15-65$ \\
\hline & $23: 30$ & $\mathrm{~T}$ & $\begin{array}{l}\mathrm{MY}, 2 \mathrm{Y}, \\
\mathrm{OW}, \mathrm{Ni}\end{array}$ & & 35 \\
\hline \multirow[t]{5}{*}{$2 \mathrm{Sept}$} & $00: 48$ & $\mathrm{~S}$ & $M Y, 2 Y$ & rough & $15-65$ \\
\hline & $03: 45$ & $S$ & $M Y, 2 Y$ & & \\
\hline & 04:00 & $\mathrm{T}$ & Pk, Sh, MY & & 35 \\
\hline & $06: 18$ & $\mathrm{~T}$ & MY & & 35 \\
\hline & $10: 12$ & $S$ & $2 \mathrm{Y}$ & & $15-65$ \\
\hline
\end{tabular}

This data set includes a large amount of transit data taken at a $35^{\circ}$ angle of incidence. This angle was the closest angle to those measured by the remote sensing satellite, 
ERS-1, that could be measured without the ship affecting the sea ice and thus disturbing the measurement.

A breakdown of the data set obtained according to ice types and whether the data were taken in transit or at a station is shown in table 3.2. A sizable amount of data were obtained from multiyear and first-year sea ice. In addition, a relatively small amount of young ice types were investigated while the ship was in transit. Data from thin ice types are useful for determining if these can be monitored from satellite-based systems such as the ERS-1 SAR. Although the experiment ended prematurely, this data set encompassed the change in sea ice backscatter during the fall freeze-up. In addition a valuable set of young ice signatures was obtained.

\begin{tabular}{|c|c|c|}
\hline \multicolumn{3}{|l|}{ Station data } \\
\hline & Number of stations & 18 \\
\hline & Multiyear stations & 13 \\
\hline & First-year stations & 5 \\
\hline & Stations with in situ & 4 \\
\hline & sea ice characterization & \\
\hline & Stations with in situ & 8 \\
\hline & snow characterization & \\
\hline & Stations with passive & 14 \\
\hline & microwave data & \\
\hline & Incidence Angles & $15^{\circ}-65^{\circ}$ \\
\hline
\end{tabular}




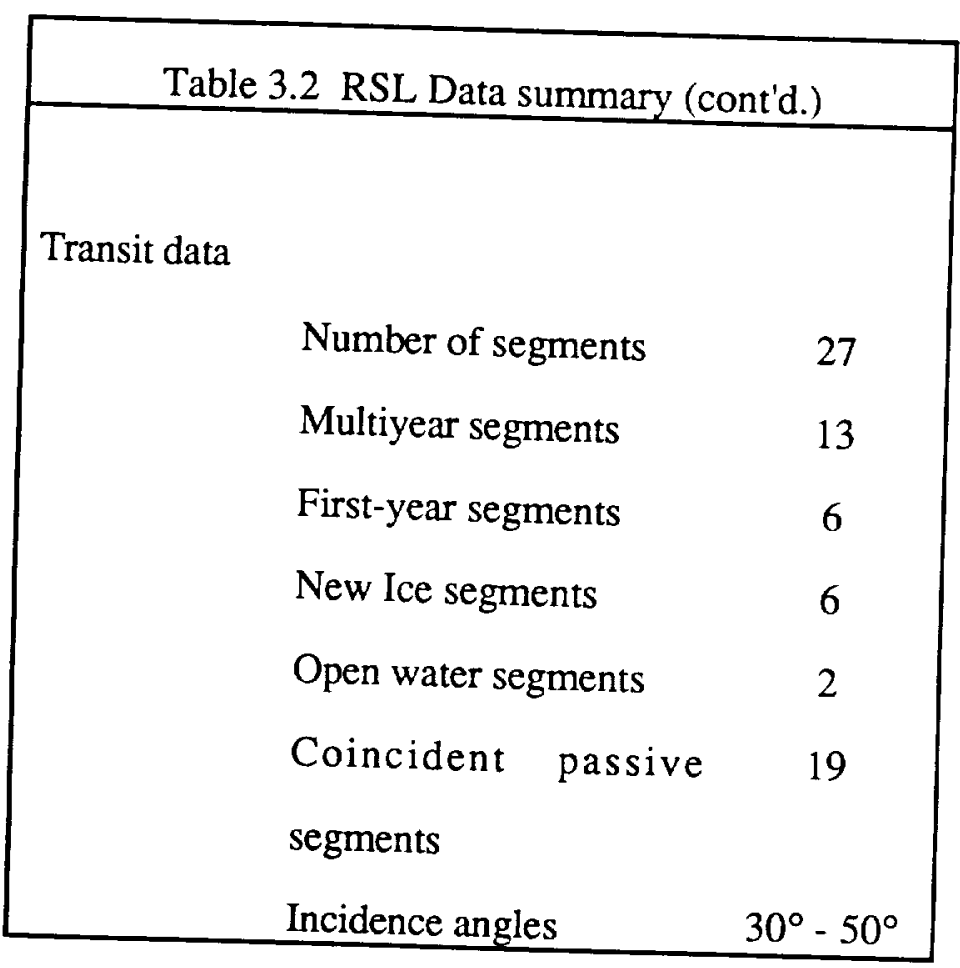

In addition to the backscatter measurements and characterization of the ice and snow, photographs of the scenes being measured were taken as both an aid in processing and interpretation. Effects due to melt ponds, for example, could be removed from the data by plotting only the portion of the angular scan for which the melt pond was not present. Also, there were cases where open water was within the angular scan of the radar and these, too, could be removed by careful scrutiny of the coincident photographs. While in transit, these photographs were taken as documentation of the ice types observed as a supplement to field notes. 


\section{Signal Processing, Calibration, and Noise Reduction}

Significant processing steps were taken to compute the backscatter coefficients from the ice types observed during IAOE'91. These steps included the removal of coherent noise sources imposed by the radar system. The noise reduction scheme and the calibration of the system are shown in this section.

\subsection{FM-CW radar signal processing}

In a linear FM-CW radar, the frequency difference between the returned signal and the transmitted signal is a measure of the range to a target. For triangular modulation this relation is [Skolnik, 1980]

$$
\mathrm{f}_{\mathrm{r}}=\frac{4 \mathrm{Rf}_{\mathrm{m}} \Delta \mathrm{f}}{\mathrm{c}},
$$

where $R$ is the range to the target, $f_{r}$ is the difference frequency, $f_{m}$ is the modulation frequency of the triangle wave, $\Delta \mathrm{f}$ is the bandwidth of the FM sweep, and $\mathrm{c}$ is the speed of light. For the system used in this study $\Delta \mathrm{f}$ was $300 \mathrm{MHz}$, resulting in a range resolution of $1 \mathrm{~m}$ in free space.

Typically, in FM-CW radar signal processing the returned waveform is sampled and averaged over a number of sweeps. This is done to improve the signal-to-noise ratio (SNR). The resulting sequence is then filtered about the return from the target and the power returned is measured and used to calculate $\sigma^{\circ}$. The bandwidth that is filtered is dependent on the distributed target range as well as the antenna beamwidth and the incidence angle. 
The backscatter coefficient for a calibrated radar system can be determined from the radar equation, using the narrow-beam approximation as

$$
\sigma^{0}=\frac{\mathrm{P}_{\mathrm{r}} \sigma_{\mathrm{cal}} R^{4} \mathrm{P}_{\mathrm{dlcal}}}{\mathrm{P}_{\mathrm{cal}} R_{\mathrm{cal}}^{4} A \mathrm{P}_{\mathrm{d} 1}}
$$

where $\mathrm{P}_{\mathrm{r}}$ is the power returned from the distributed target and $\mathrm{P}_{\mathrm{cal}}$ is the power returned from a calibration target of known radar cross section, $\sigma_{\text {cal }}$. The parameters $\mathrm{P}_{\mathrm{dlcal}}$ and $\mathrm{P}_{\mathrm{dl}}$ are the delay line readings taken at the time of calibration and the time of the field measurement, respectively. The range to the distributed target is $\mathrm{R}, \mathrm{A}$ is the area illuminated by the antenna, and $R_{c a l}$ is the range to the calibration target.

The returned power is taken as the total power returned from the illuminated surface. The illuminated area is computed from [Ulaby, et al., 1982] as,

$$
A_{\text {ill }}=\frac{\pi}{2} R_{0}^{2} \cos \left(\theta^{\text {inc }}\right) \tan \left(\frac{\beta_{\mathrm{az}}}{2}\right)\left[\tan \left(\theta^{\text {inc }}+\frac{\beta_{\mathrm{el}}}{2}\right)-\tan \left(\theta^{\text {inc }}-\frac{\beta_{\mathrm{cl}}}{2}\right)\right],
$$

where $\beta_{\mathrm{az}}$ and $\beta_{\mathrm{el}}$ are the antenna's azimuth and elevation beamwidth, respectively. The angle of incidence is denoted by $\theta^{\text {inc }}$ and the range to the surface, $R_{O}$ is calculated from the relationship in (4.1). The range is corrected for delays in the system itself by simply subtracting the system delay from the range measured. The determination of the system delay is based on knowledge of the range to the calibration target, which was measured during calibration.

\subsection{Coherent noise reduction}

The IF spectra of non-ideal radar systems consist of systematic noise sources due to a variety of factors. These include, but are not limited to, mismatch errors in the RF components, antenna feedthrough and multiple reflections in the RF subsection. The effect of these noise sources is to inject narrow bandwidth spikes into the IF spectrum. 
These noise sources are systematic and coherent and therefore may be removed from the spectrum if processed properly. To remove these one would require measurements taken by the radar system in which there is no target present. This is typically referred to as a "sky" measurement, since at the lower microwave frequencies this corresponds to a measurement in which there is no target present. The sky measurement would need to be coherently subtracted (in the "time" domain or frequency domain) from the signal obtained when a target is present in order to remove coherent, systematic noise sources.

During IAOE'91 the radar mount was physically limited so that a sky measurement could not be used. The largest incidence angle that could be obtained was $65^{\circ}$ off nadir. The power returned at large incidence angles is typically small. Also, the bandwidth corresponding to a $65^{\circ}$ measurement is sufficiently separated in frequency from the returns at other incidence angles. These two characteristics allow for the $65^{\circ}$ measurements to be used for systematic, coherent noise estimates. To obtain the measurement of $\sigma^{\circ}$ at $65^{\circ}$ the $15^{\circ}$ return was used as the measure of coherent noise. This is effective because the interference of the actual return from the ice surface at $15^{\circ}$ occurs in a different portion of the spectrum than the higher angle returns. This technique was applicable for stations in which angular scan data were taken.

For data sets in which angular scans were not obtained a second, related approach had to be employed. While the ship was in transit only a single angle of incidence was typically used for measurements. Therefore, the coherent noise removal scheme described in the preceding paragraph was not suitable for use with these data. The second coherent noise removal scheme was based on the fact that the systematic noise sources are coherent and the returns from the surface are not. 
In this scheme, all the raw data from the measurements within some time frame (usually one to two hours) were averaged together as an estimate of the coherent noise present in the system. This noise estimate was then coherently subtracted from each of the measurements to produce an improved spectrum and an improved estimate of the returned power.

\subsection{Coherent noise reduction results}

The spectrum of the radar measurements was greatly improved with the coherent subtraction technique. In addition to this measurements in which the target's location corresponded to a systematic noise source location in the spectrum were retrieved. The measurements at these ranges would have been useless without the coherent noise reduction technique The following plots demonstrate the usefulness of the technique.

Figures 4.1 through 4.4 show the spectra of several returns from sea ice for varying angles of incidence before and after the primary coherent noise removal technique was applied to the data. The $15^{\circ}$ return demonstrates that when the signal is far enough above the coherent noise, as well as in a different portion of the spectrum, the measured power returned will not differ from the original case. The comparisons at other angles demonstrate the capability of this technique to remove the noise sources inherent in the radar system. The $20^{\circ}$ return in figure 4.2 shows the effect of the coherent noise being almost completely correlated with the original return (dashed line) so that the location of the return is not visible. When the coherent noise is removed, however, the return (solid line) can be clearly seen. 
The results from applying the second technique, which requires averaging the set of measurements and is required for computing $\sigma^{\circ}$ for transit data, are demonstrated in figure 4.5. Here we see that the "noise spikes" are clearly reduced and that a clean return from the sea ice is visible.

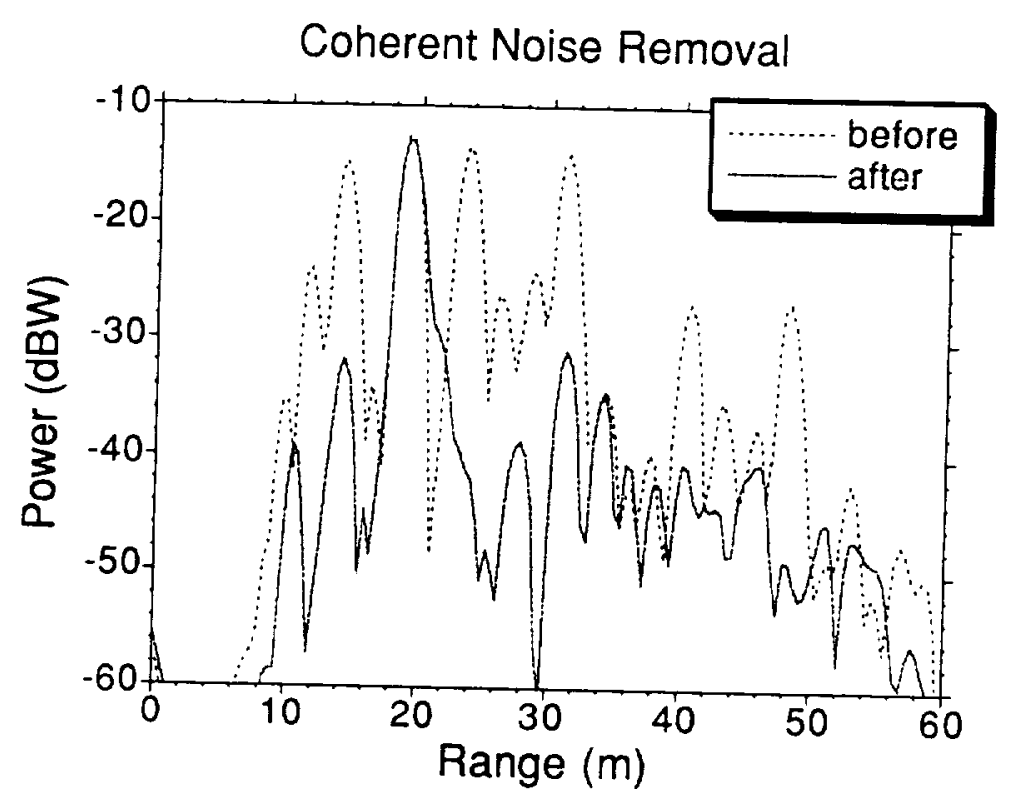

Figure 4.1. Returned power for a measurement at $15^{\circ}$ before and after coherent noise removal. 


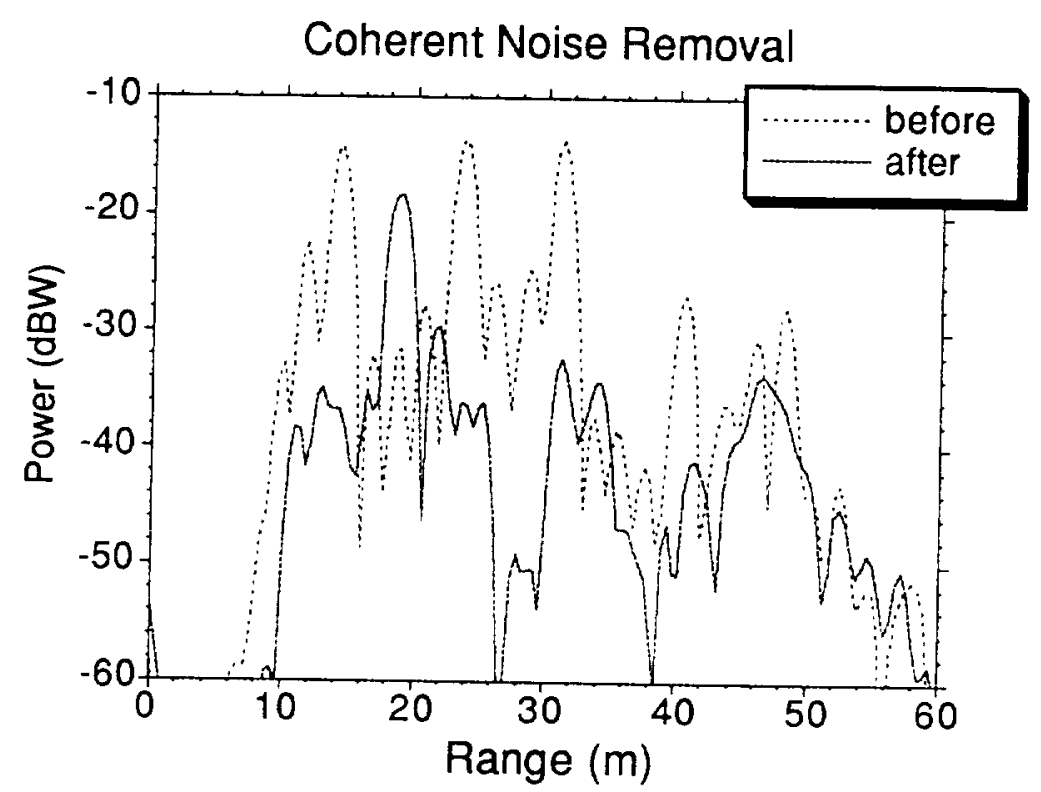

Figure 4.2. Returned power for a measurement at $20^{\circ}$ before and after coherent noise removal.

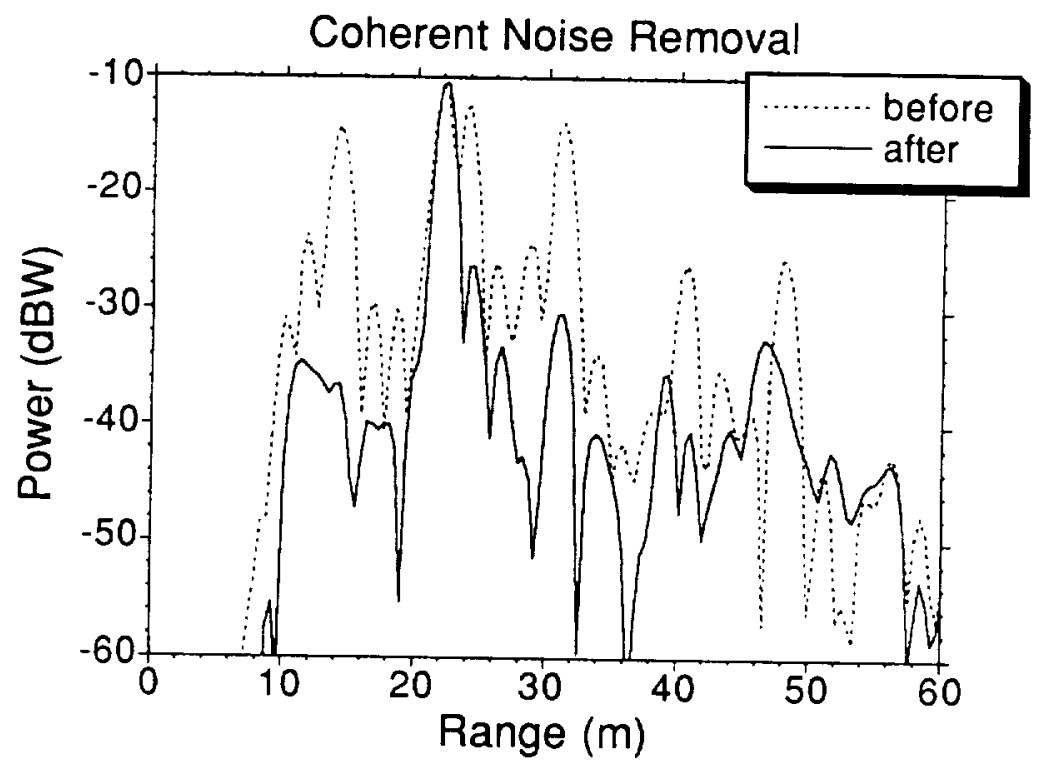

Figure 4.3. Returned power for a measurement at $35^{\circ}$ before and after coherent noise removal. 


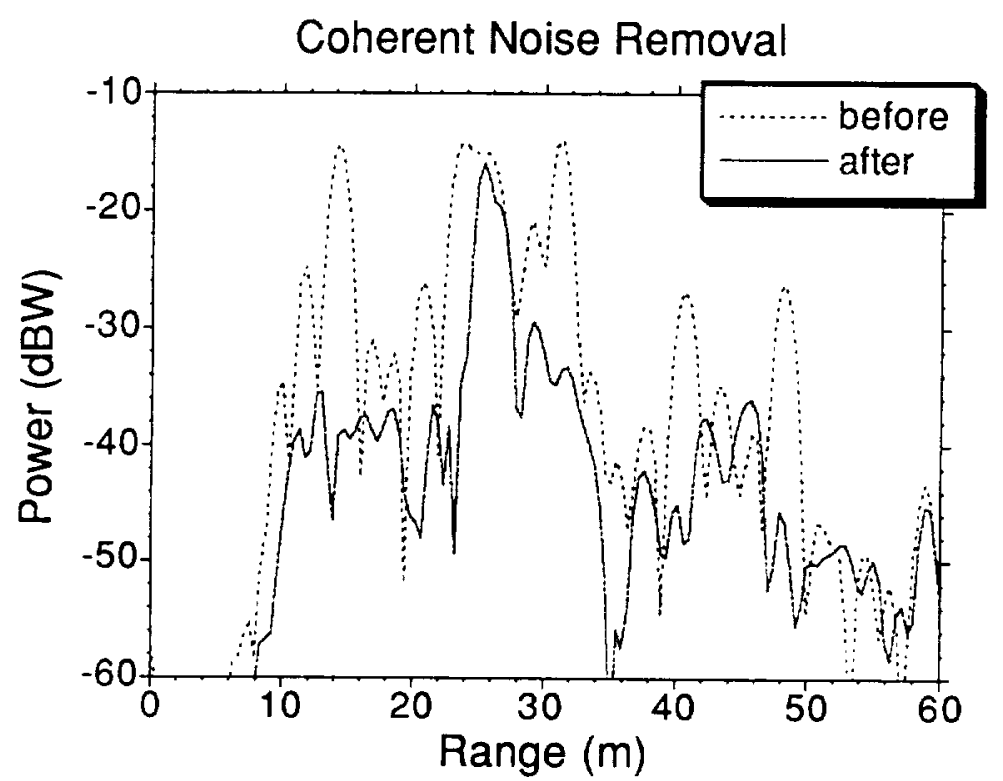

Figure 4.4. Returned power for a measurement at $45^{\circ}$ before and after coherent noise removal.

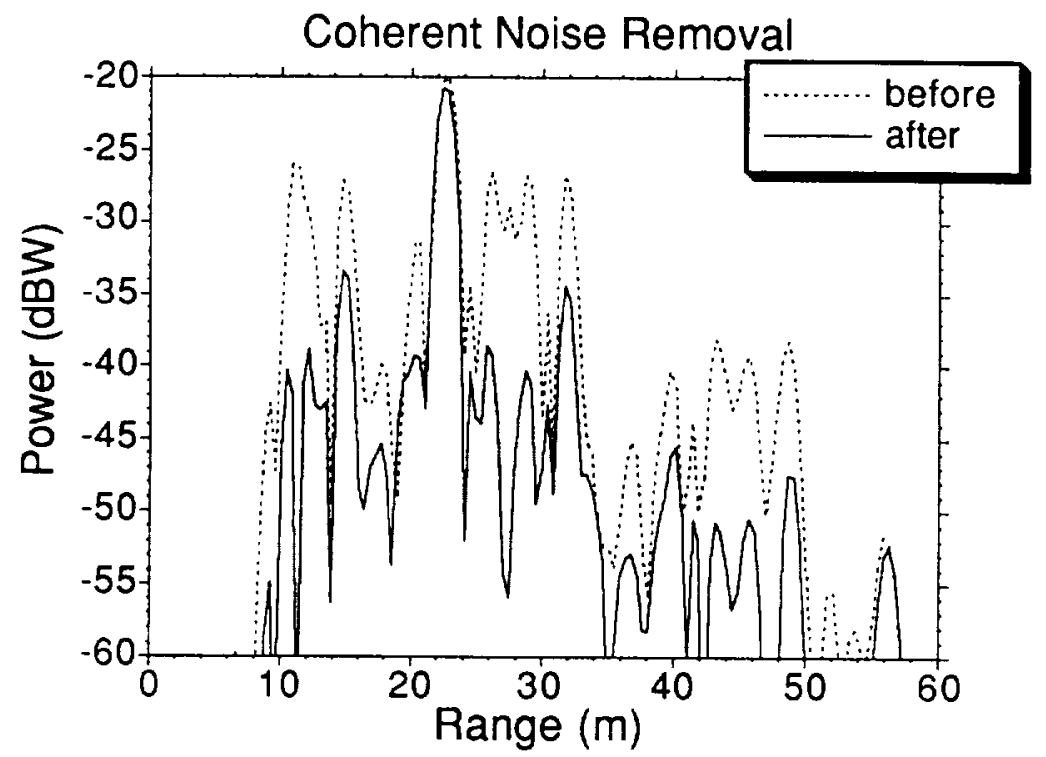

Figure 4.5. Returned power for transit data measurement at $35^{\circ}$ before and after coherent noise removal. The coherent noise estimate in this case is the average of 18 returns, all of which were taken at $35^{\circ}$ incidence angle. 


\subsection{Radar calibration}

Due to the narrow beamwidth of the offset-parabolic reflector antenna, external calibration in the field was difficult. A single external calibration was carried out midway during the experiment on 29 August 1991. Internal calibrations, using delay lines, were performed with each measurement sample to adjust for the possible changes in the system throughout the experiment. The daily average of the delay line measurements were found to vary by less than $2 \mathrm{~dB}$ throughout the experiment as demonstrated by figure 4.6. Each data point is the average over a single ice station.

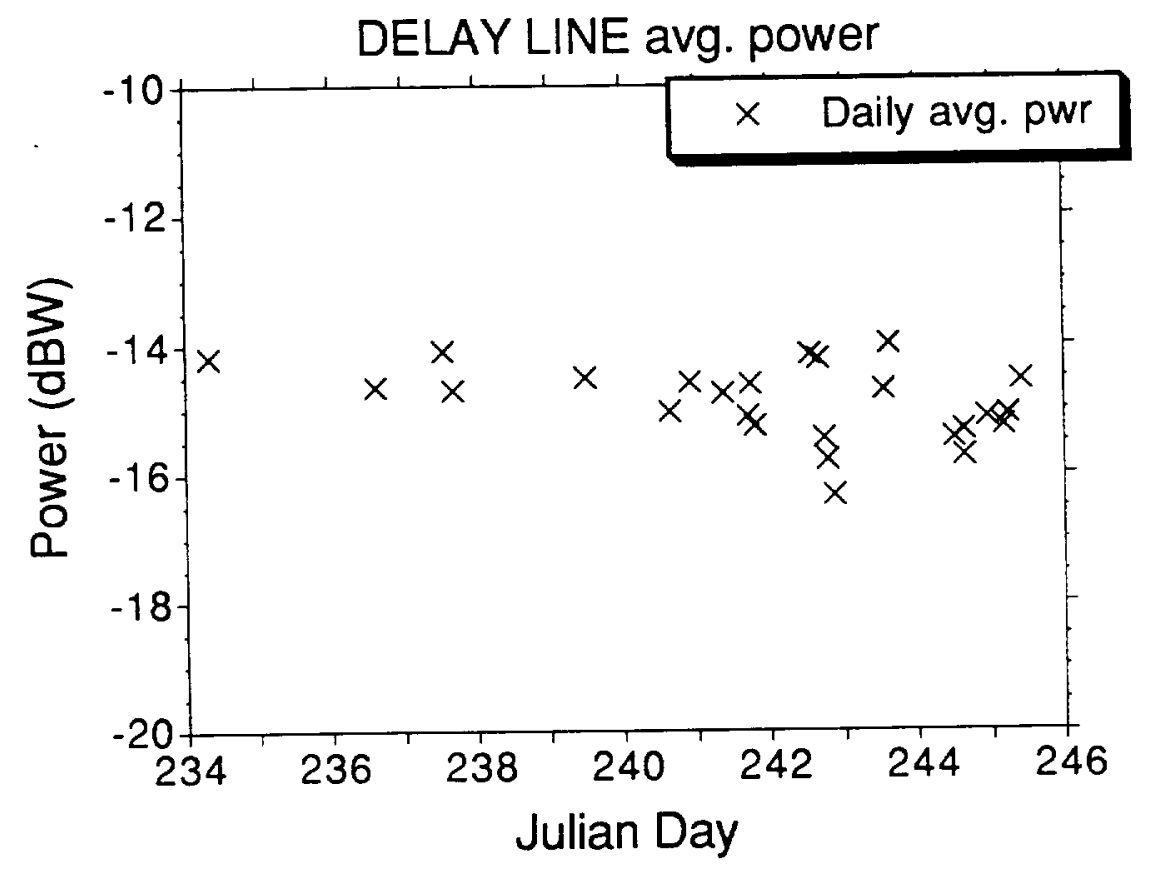

Figure 4.6. Delay-line measurement variations.

The average over the entire experiment was $-14.9 \mathrm{dBW}$ with a standard deviation of

$0.58 \mathrm{~dB}$. This plot clearly demonstrates that the delay line readings were always within $\pm 1 \mathrm{~dB}$ of the mean value over the entire experiment and that there is no dramatic 
change or general trend in the system's function throughout the course of the experiment.

The external calibration was performed by measuring the return from a 16 -inch diameter Luneburg lens. The absolute cross section of this target was obtained from past measurements [Bredow, 1989].

The IF spectrum for the lens measurement is shown in figure 4.7. Here the VV and $\mathrm{HH}$ returns are shown as a function of the IF frequency. The range to the target is determined by equation 4.1 as discussed previously.
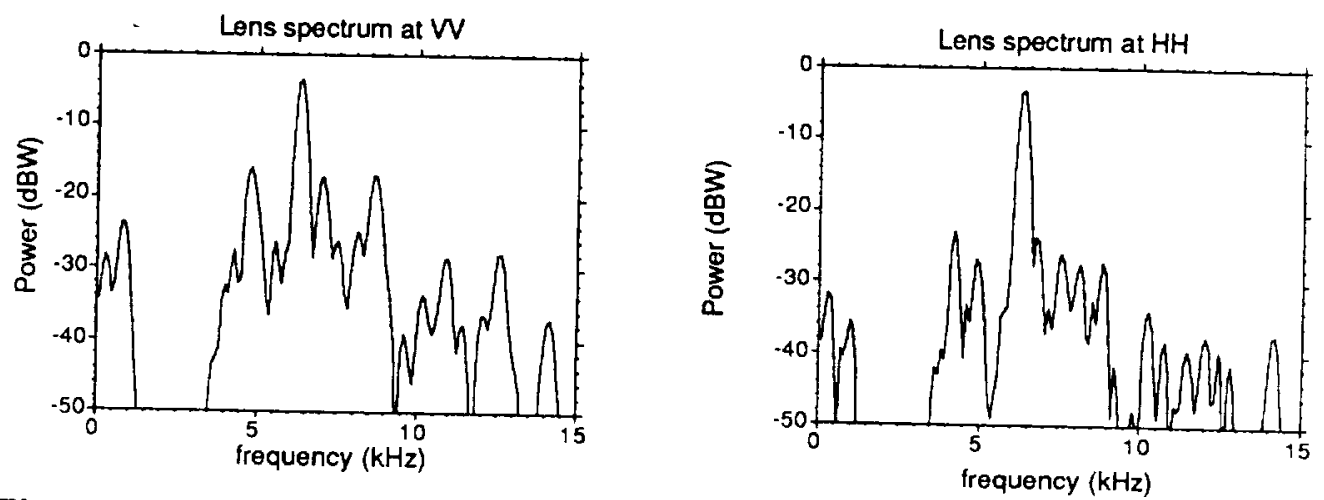

Figure 4.7 Returned power spectrum for the Luneburg lens at both $\mathrm{VV}$ and $\mathrm{HH}$ polarizations.

These spectra demonstrate the high SNR in the frequency range that includes the return from the lens. The return from the lens comes in the range 6.3 to $6.4 \mathrm{kHz}$. The other sub-peaks in these spectra are the systematic noise sources discussed in section 4.2. There was no need to remove these effectsbecause of the high signal-to-noise ratio (SNR) for the lens return. The power returned from the Luneburg lens was used in equation 4.2 for the calculation of the backscatter coefficient. 


\section{In situ Geophysical Information}

Snow properties and meteorological information were recorded for each of the stations in which backscatter data were taken during IAOE'91. Sea ice characterization included salinity, density and temperature profiles at some stations, as well as a few measurements of surface roughness. The snow parameters measured include depths, snow temperature, snow-ice interface temperature, permittivity, density and salinity, as well as grain size. The sea ice characterization was performed by the CRREL group and the in situ snow data were collected by MWG. Meteorological data were recorded as standard operating procedure aboard the Polar Star by the scientific crew.

Due to the early end of Polar Star's participation in IAOE'91, the CRREL group had to begin shutting down their operations on 30 August. Because of this, coincident ice property data were collected in only three instances where microwave backscatter measurements were made. There were nine coincident ice stations where passive microwave measurements and snow characterization were performed by MWG and four stations where small-scale roughness was measured. Black-and-white photographs of the radar footprint areas were acquired for most of the fixed stations transit locations.

\subsection{In situ snow data}

The measurements of the snow parameters for each of the scatterometer data stations are listed in table 5.1. As the temperature dropped during the experiment the amount of snow cover increased. This resulted in a change from wet, high density snow with large grain size to a drier fresh snow cover of lower density and smaller grain size. 
Table 5.1 In situ snow measurements

\begin{tabular}{|c|c|c|c|c|c|}
\hline \hline Station & $\begin{array}{c}\text { depth } \\
(\mathrm{cm})\end{array}$ & $\begin{array}{c}\text { density } \\
\left(\mathrm{kg} / \mathrm{cm}^{3}\right)\end{array}$ & $\begin{array}{c}\text { wetness } \\
(\% \text { by vol })\end{array}$ & $\begin{array}{c}\text { grain size } \\
(\mathrm{mm})\end{array}$ & $\begin{array}{c}\text { surface } \\
\text { permittivity }\end{array}$ \\
\hline FY2208 & 0.5 & 319.6 & $2-5$ & $1-5$ & $1.48-2.65$ \\
\hline MY2408 & 1.0 & 196 & $1.2-1.5$ & 5 & $1.28-1.29$ \\
\hline MY2708 & 0.5 & 312.2 & 0.9 & $5-10$ & $1.28-1.76$ \\
\hline MY2908 & $0.5-4.5$ & 266.9 & not obtained & $1-3$ & $1.27-1.33$ \\
\hline MY3008 & $0.5-3$ & 263.2 & not obtained & $1-5$ & $1.33-1.40$ \\
\hline MY3108 & $6-12$ & 257 & $0.1-0.2$ & 1 & $1.20-1.38$ \\
\hline MY0109B & $5-10$ & $114.7-211.1$ & $0.1-0.5$ & $1-3$ & $1.22-1.41$ \\
\hline FY0209. & $3-4$ & $147.6-287.8$ & $0.4-0.5$ & 1 & $1.34-1.49$ \\
\hline
\end{tabular}

\subsection{In situ sea ice data}

The temperature and salinity profiles of the sea ice were measured by the CRREL group for the ice stations taken on 22, 27, and 29 August. These profiles are plotted in figures 5.1, 5.2, and 5.3. These demonstrate that the sea ice at the station where measurements were taken on 22 August had higher salinity than the other stations. Typically, cold first-year ice has bulk salinities ranging from 3 to $6 \%$ and second-year and multiyear ice have salinities ranging from about 1 to $2 \%$. The first-year salinity profile here, however, is approaching the second-year ice profile published previously [Wadhams, 1992]. This is due to the fact that these data were collected at the end of the summer melt, just prior to the fall freeze-up. 


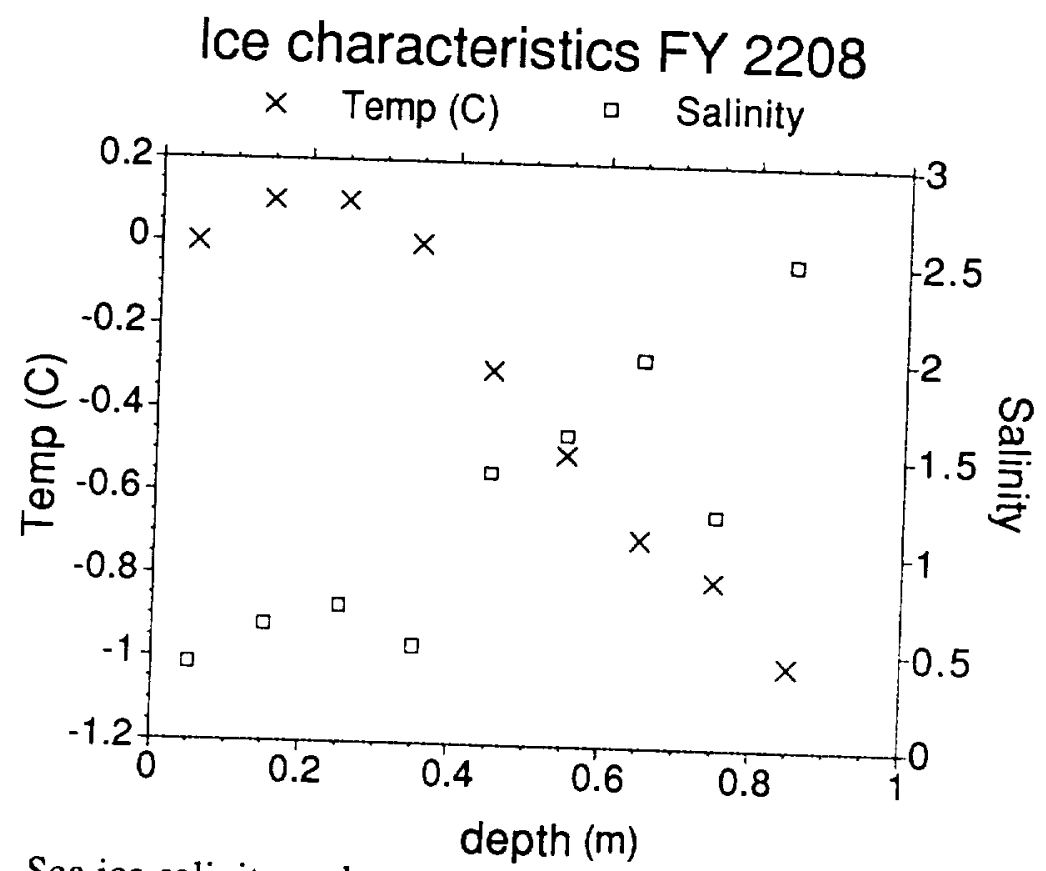

Figure 5.1. Sea ice salinity and temperature profiles, taken coincidently with the first-year sea ice station data of 22 August, 1991. The salinity is in \%o.

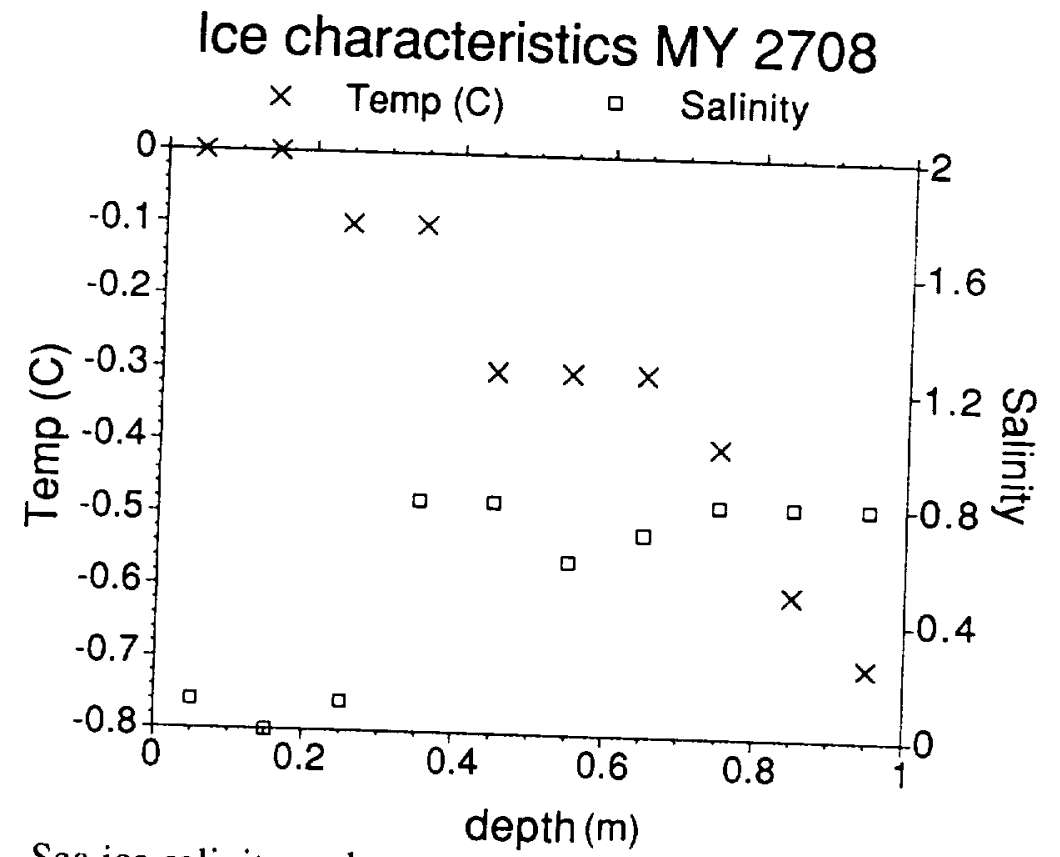

Figure 5.2. Sea ice salinity and temperature profiles, taken coincidently with the multiyear sea ice station data of 27 August, 1991. The salinity is in \%o. 


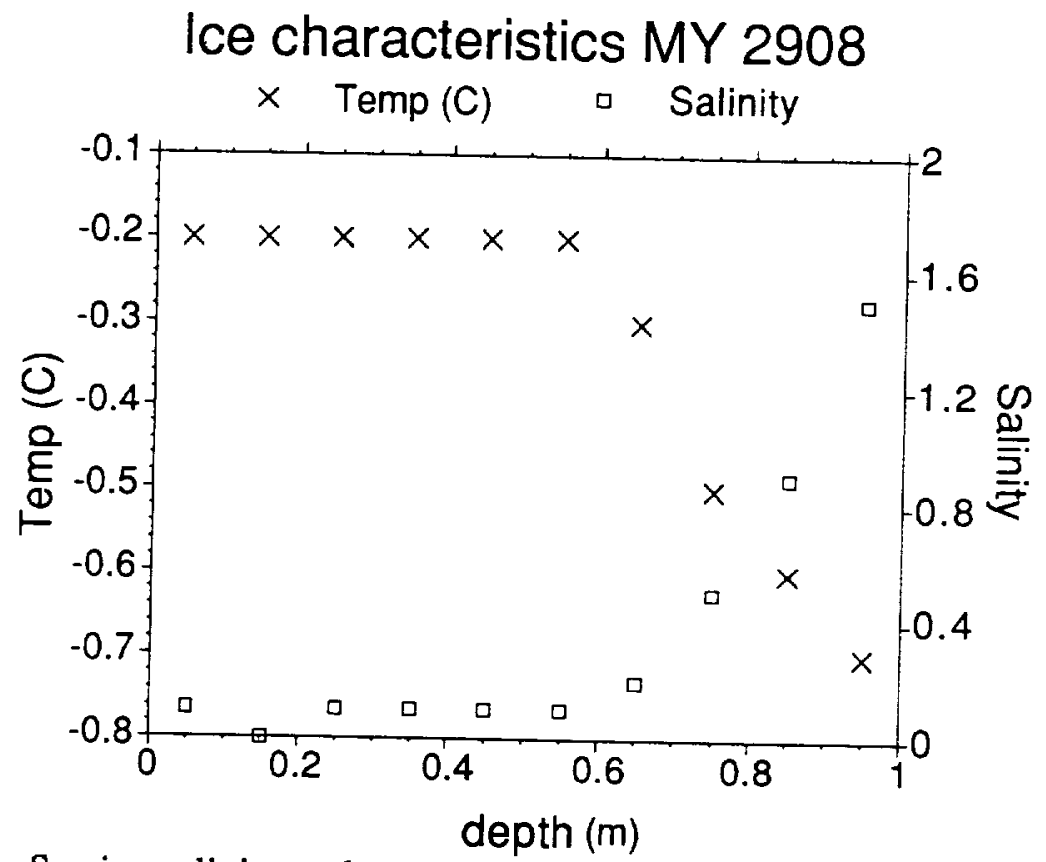

Figure 5.3. Sea ice salinity and temperature profiles, taken coincidently with the multiyear sea ice station data of 29 August, 1991. The salinity is in \%o.

The density profiles for the same three stations are shown in figure 5.4. These demonstrate that the first-year ice station contained sea ice of slightly lower density than that of the multiyear ice stations. At this time of year, the first-year sea ice is similar to multiyear sea ice in terms of its density. The fluctuation of the density with depth is primarily due to differences in the bubble structure in the sea ice with depth. 


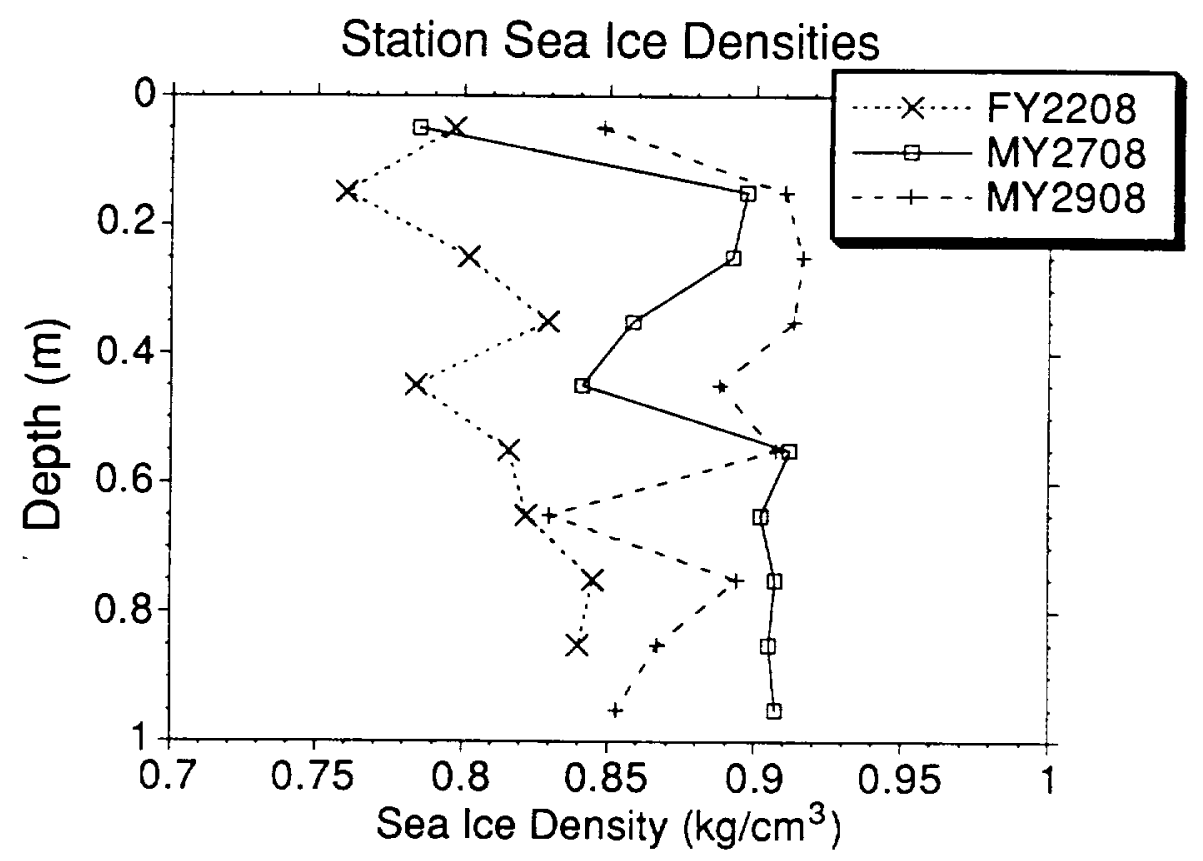

Figure 5.4 Sea ice density profiles for the three coincident sea ice stations 


\section{Sea Ice Backscatter Measurement Results}

The coherent noise removal techniques were applied to all measurements acquired

during IAOE'91, and the resulting spectra were then used to compute power returned from the sea ice. The backscatter coefficient was calculated from these measurements. Up to four measurements were taken at each angle for the station data and averaged to produce an estimate of the true $\sigma^{\circ}$. The measurements acquired during transit were divided according to the ice type and resulting distributions are presented in this section.

\subsection{Sea ice station measurements}

There were 13 stations in which the angular measurements of the radar backscatter were taken. The resulting angular responses are shown in figures 6.1 through 6.13. These are shown in chronological order and are labeled either as first-year, second-year, or multiyear ice. The first-year ice stations in the latter portion of the experiment may be considered as second-year ice stations due to the onset of the fall freeze-up. In this study, as well as a second expedition in the Arctic at the same time [Carlstrom, personal communication] there is very little difference between the signatures of multiyear sea ice and second-year sea ice after the freeze-up. Photographs of the footprint area are shown along with the backscatter data. These aid in interpreting the variations in the angular response of the backscatter due to physical differences of the sea ice across the footprint. These physical differences include melt ponds and ridges. 

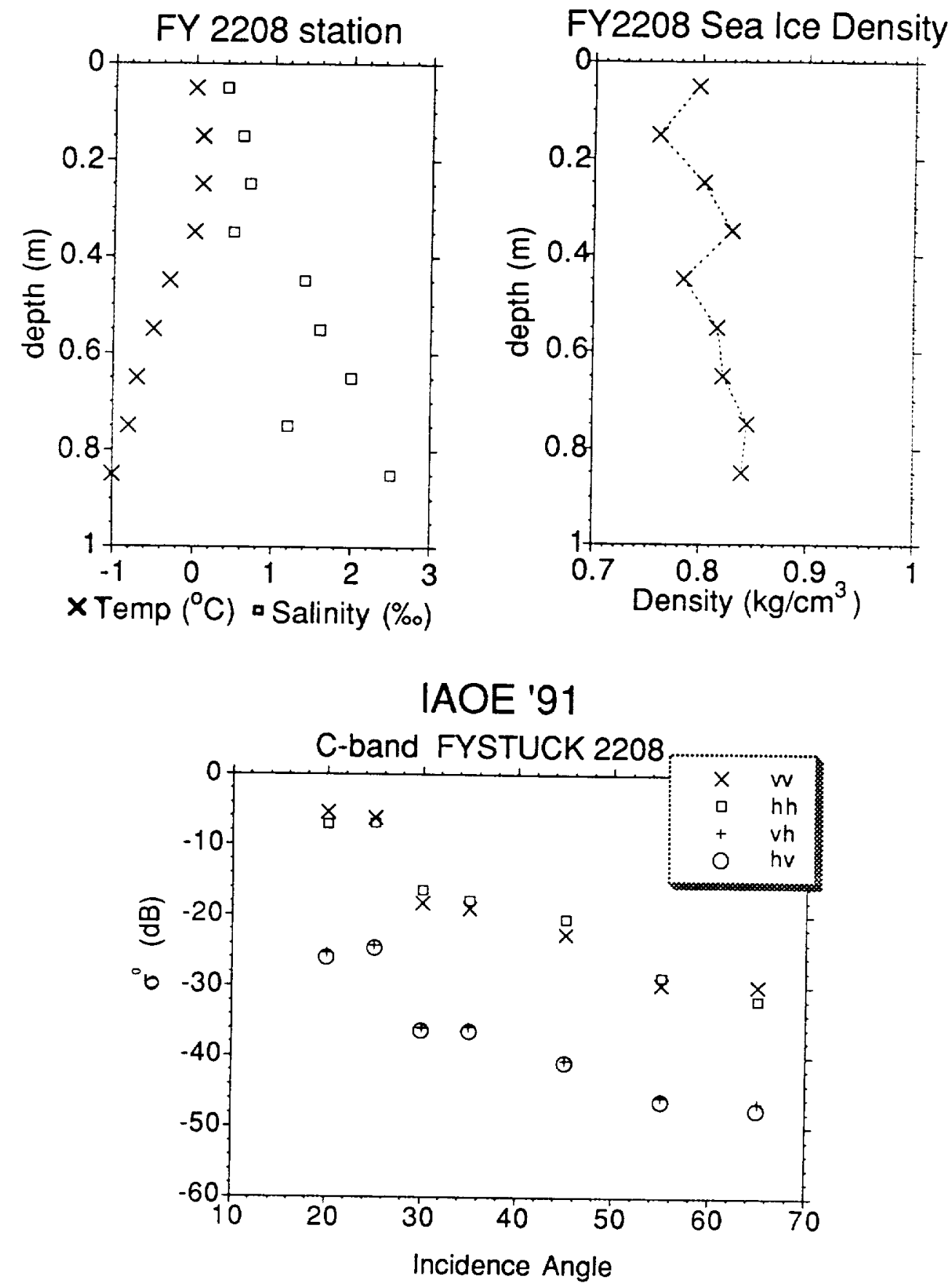

Figure 6.1. Backscatter coefficient for first-year sea ice with coincident temperature salinity, and density profiles. Measurements were performed on 22 August, 1991. 


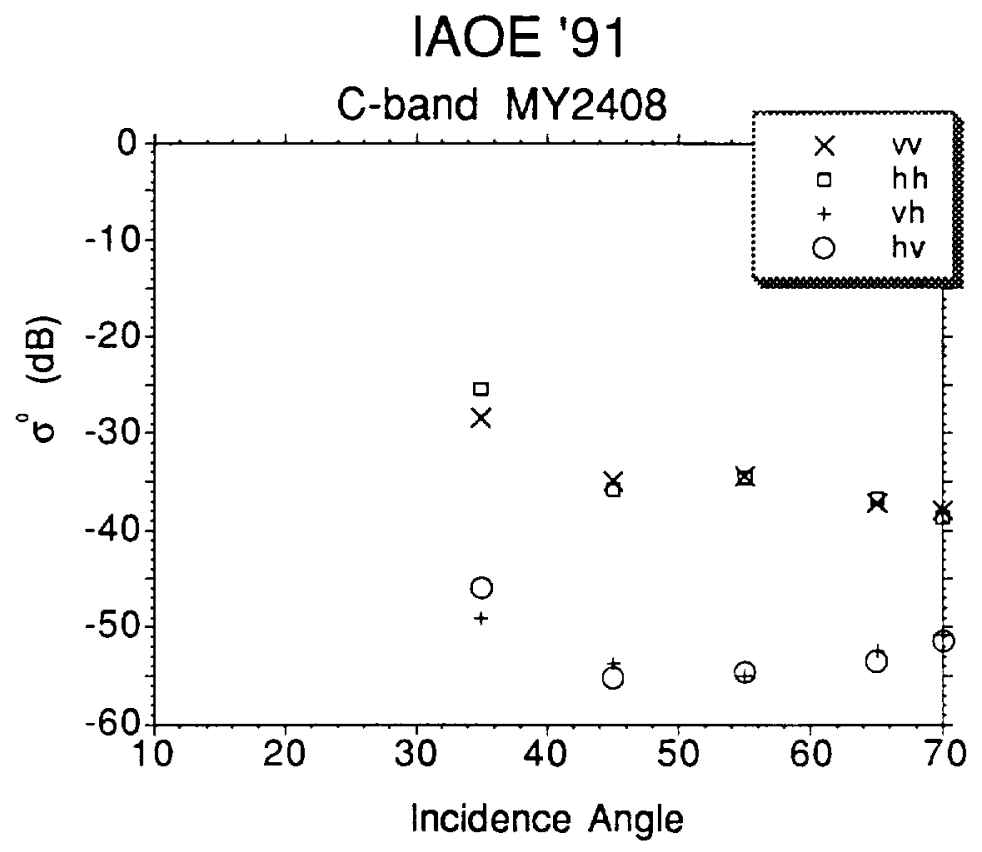

Figure 6.2. Backscatter coefficient for multiyear sea ice. Measurements were performed on 24 August, 1991.

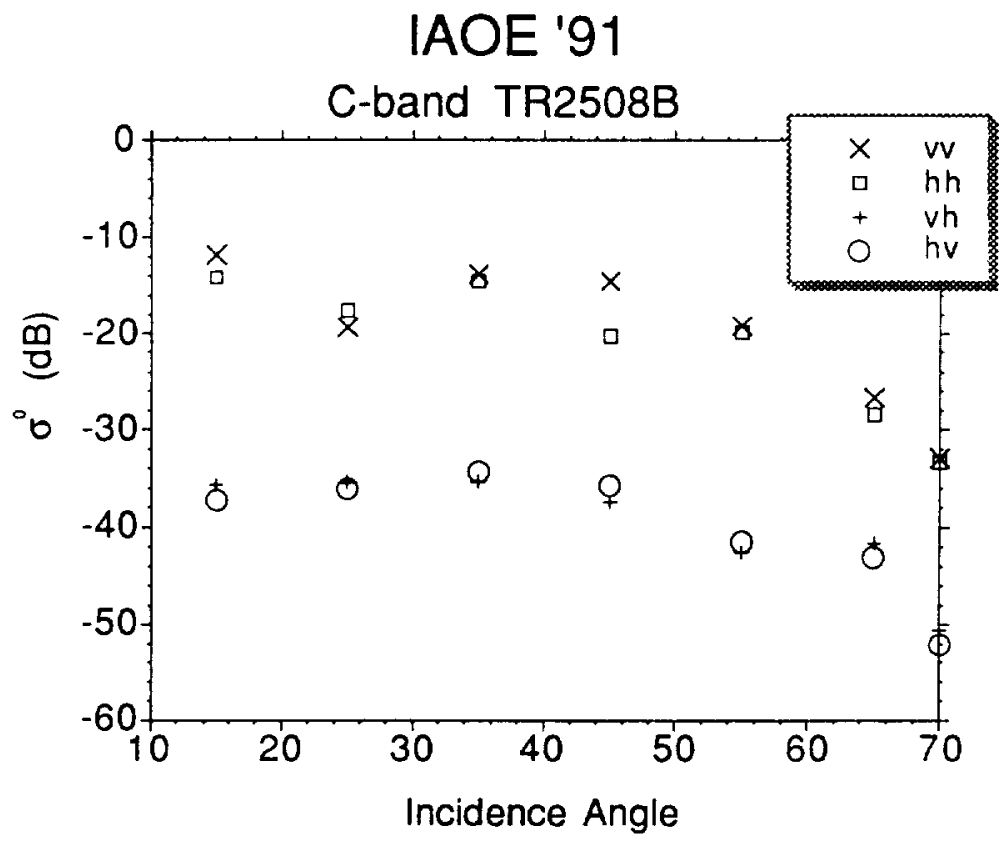

Figure 6.3. Backscatter coefficient for multiyear sea ice. Measurements were performed on 25 August, 1991. 

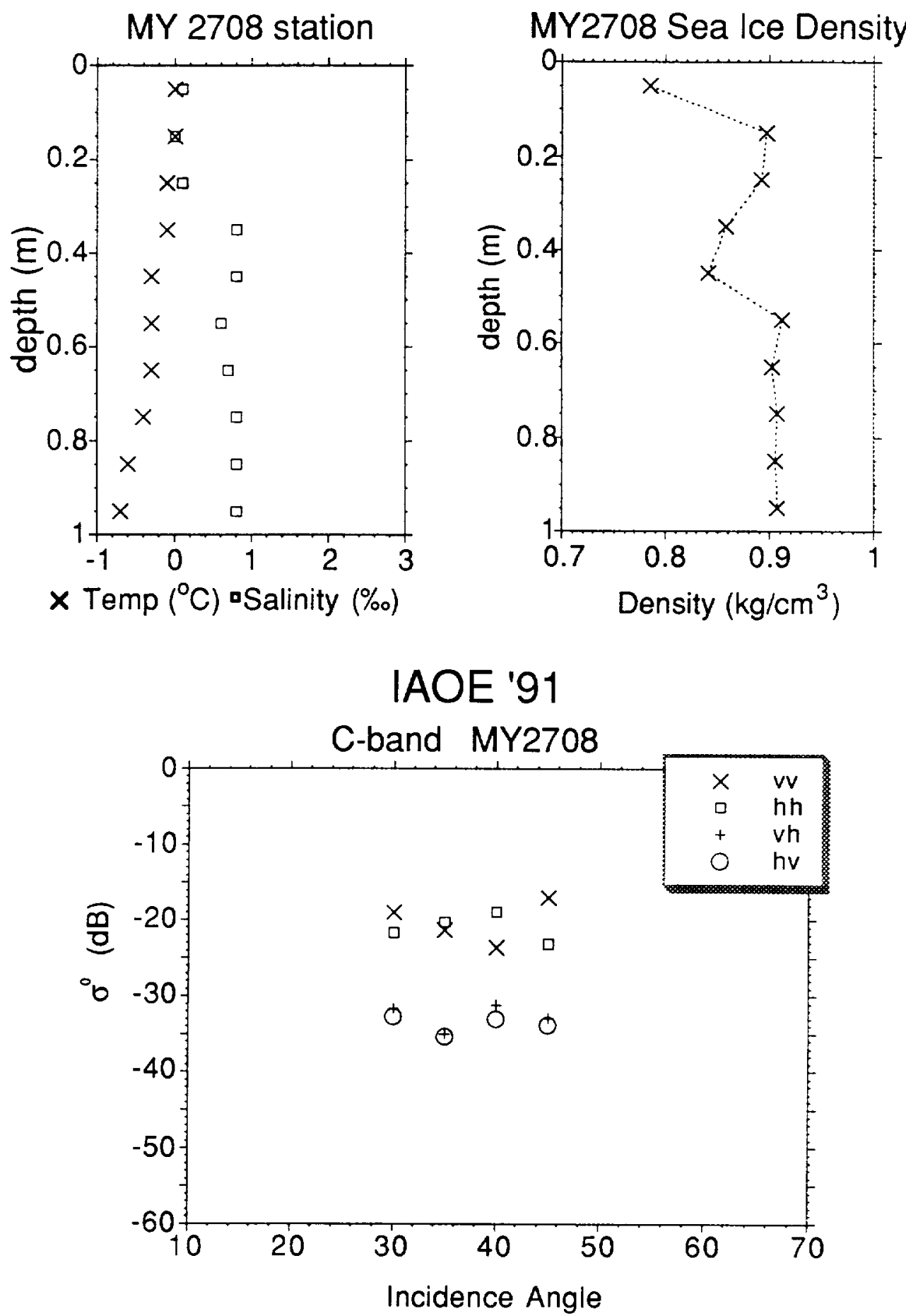

Figure 6.4. Backscatter from multiyear sea ice with coincident temperature, salinity, and density profiles. Measurements were performed on 27 August, 1991. 

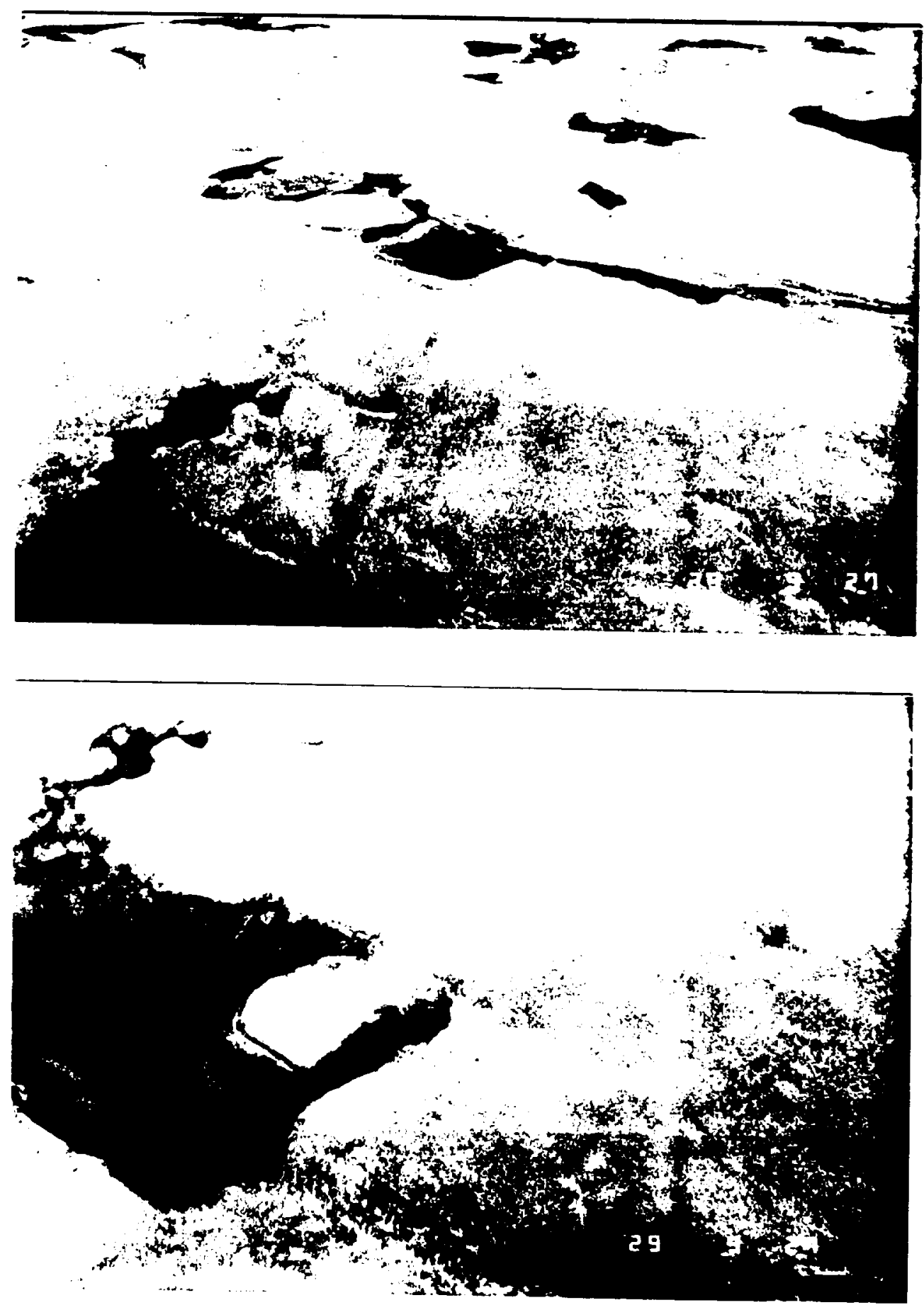

Photograph 6.1 Appearance of the scene for the data taken on MY2908 multiyear sea ice floe for (a), low angles of incidence and (b), higher angles. The melt ponds appear to affect the measurement at $30^{\circ}, 40^{\circ}$ and $55^{\circ}$. 

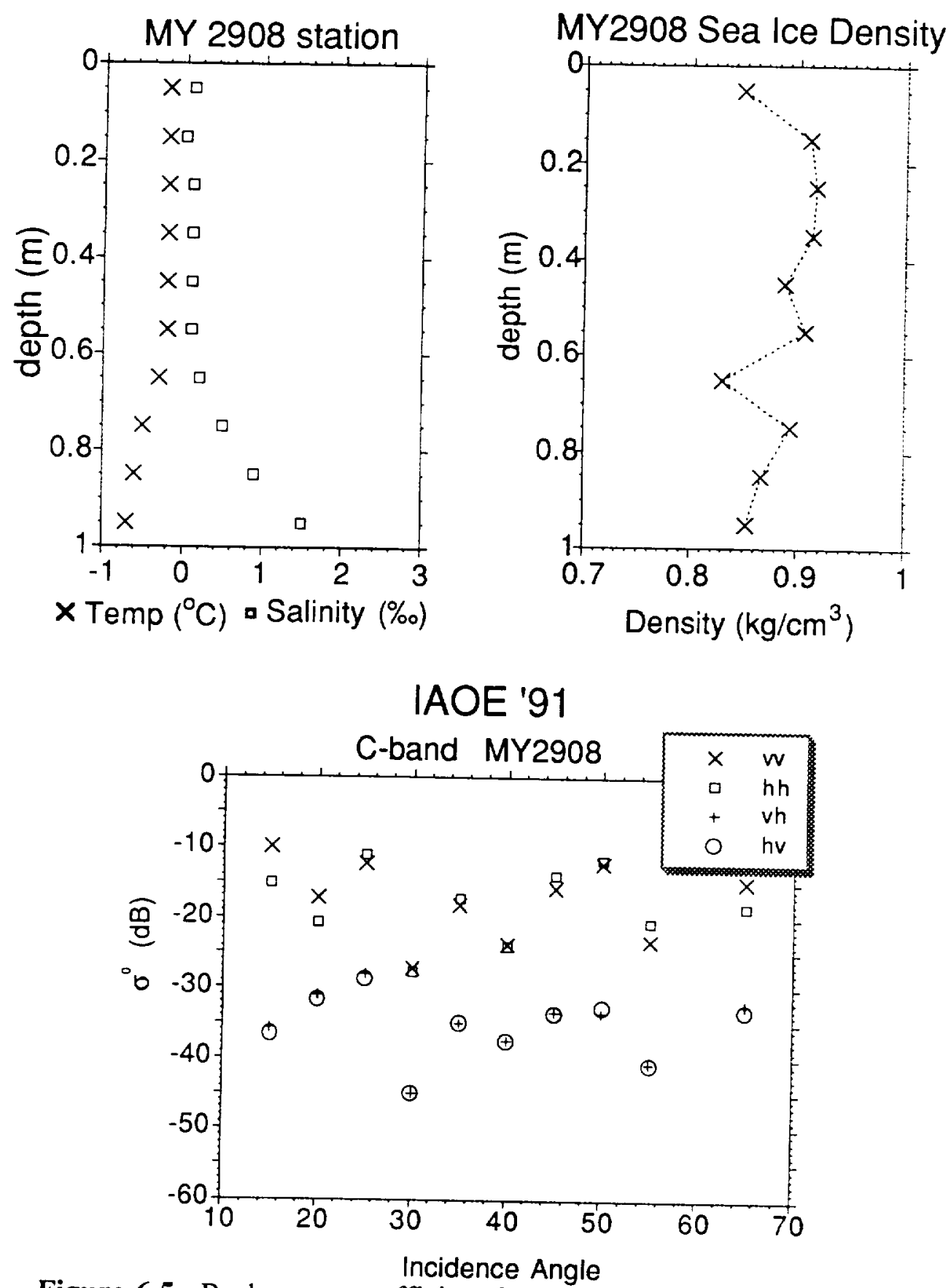

Figure 6.5. Backscatter coefficient for multiyear sea ice with coincident temperature, salinity, and density profiles. Measurements were performed on 29 August, 1991 . The dips in the backscatter at $30^{\circ}, 40^{\circ}$, and $55^{\circ}$ are due to melt ponds in the radar footprint as seen in photograph 6.1. 


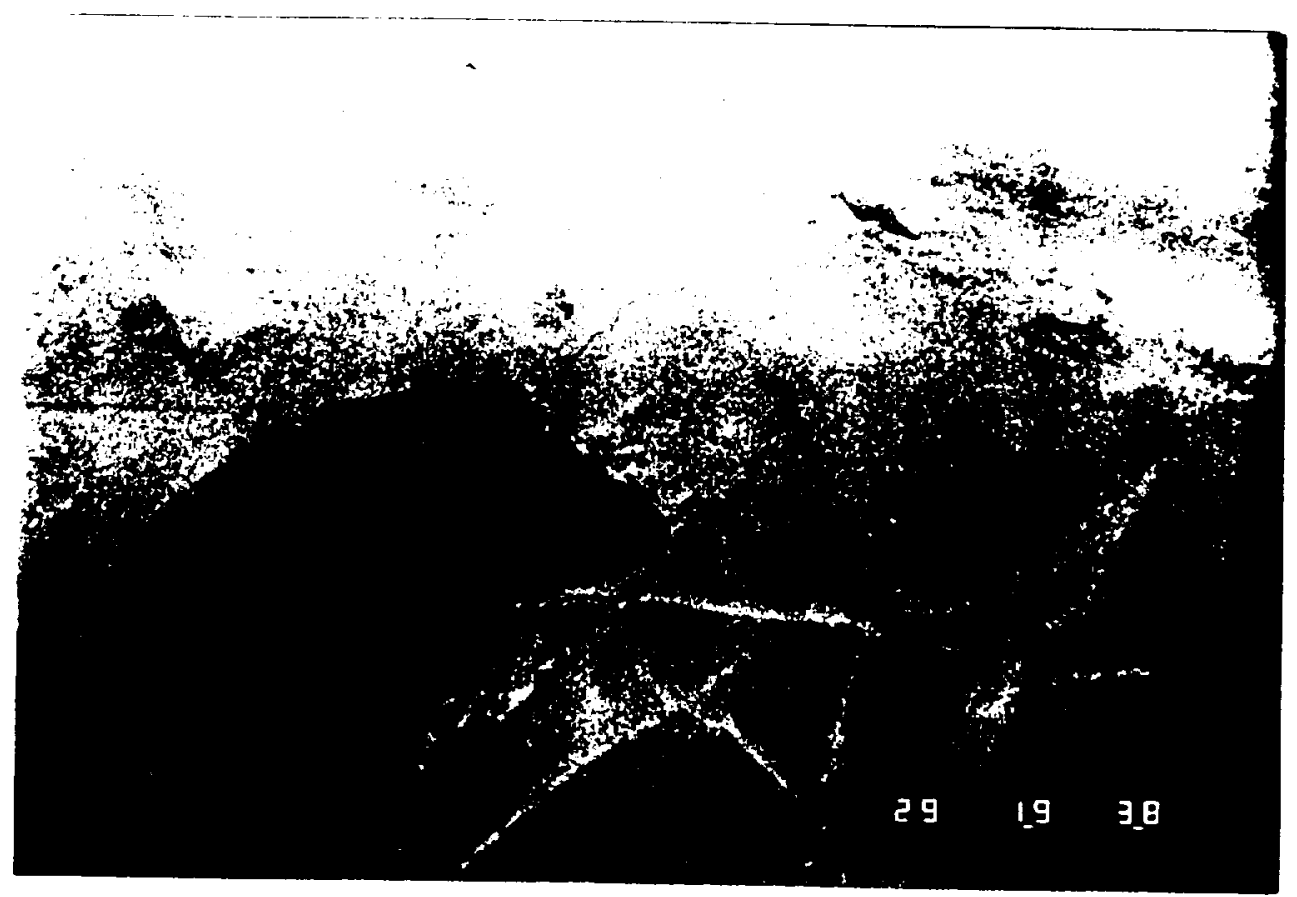

Photograph 6.2 Appearance of the scene for the data taken on TR2908C multiyear sea ice floe. The micro-ridge in the higher angles appears to contribute to an increase in the backscatter as shown in figure 6.6 below.

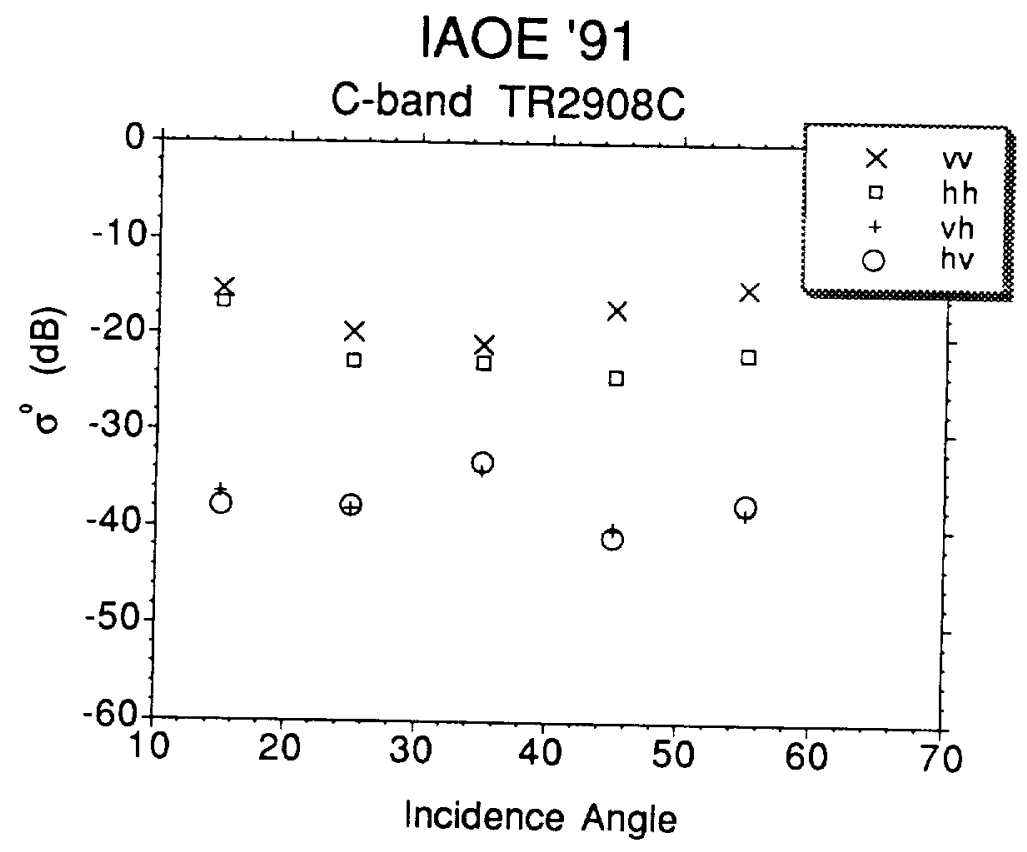

Figure 6.6. Backscatter coefficient for multiyear sea ice. Measurements were performed on 29 August, 1991. 


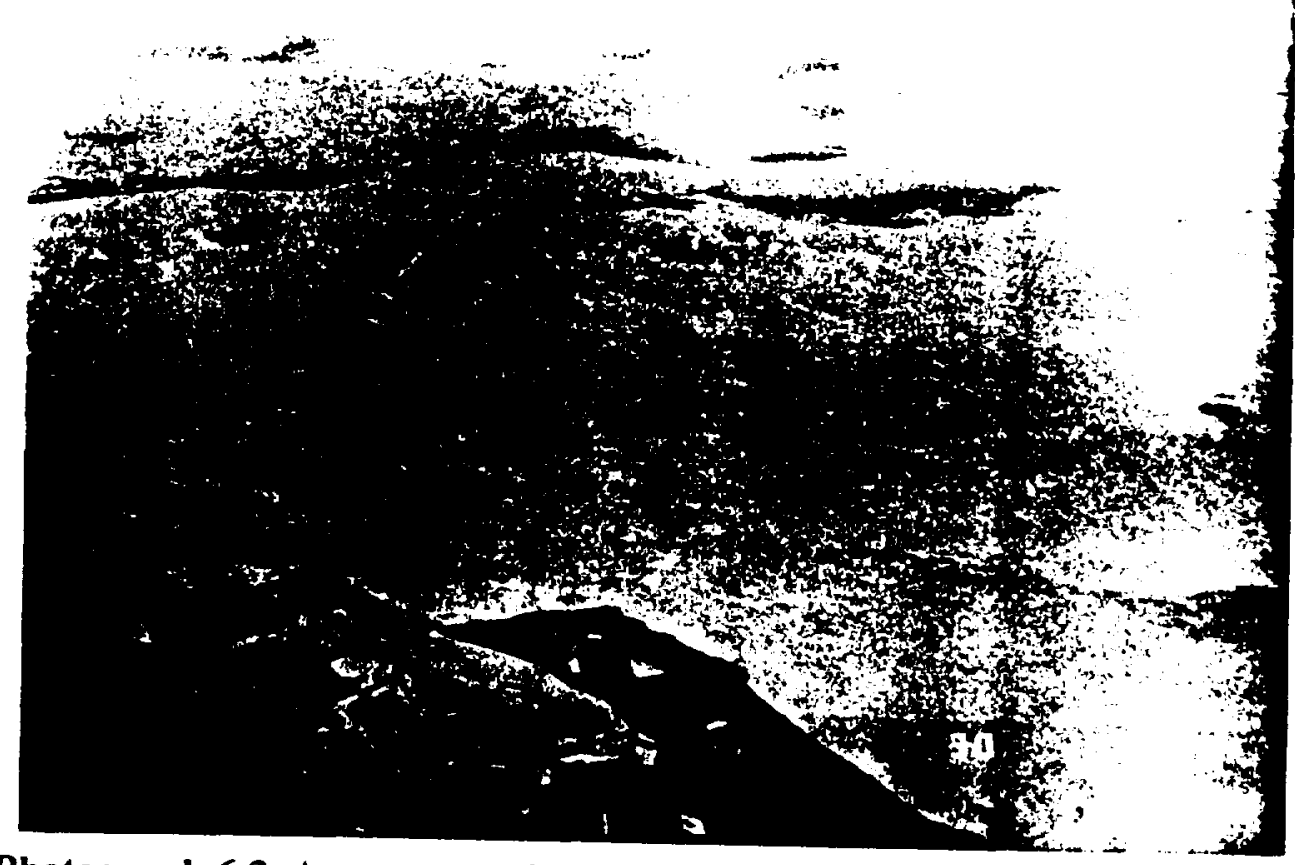

Photograph 6.3 Appearance of the scene for the data taken on the FY3008 second-year sea ice floe. The smooth characteristic of late first-year ice results in the backscatter characteristics shown in figure 6.7 below.

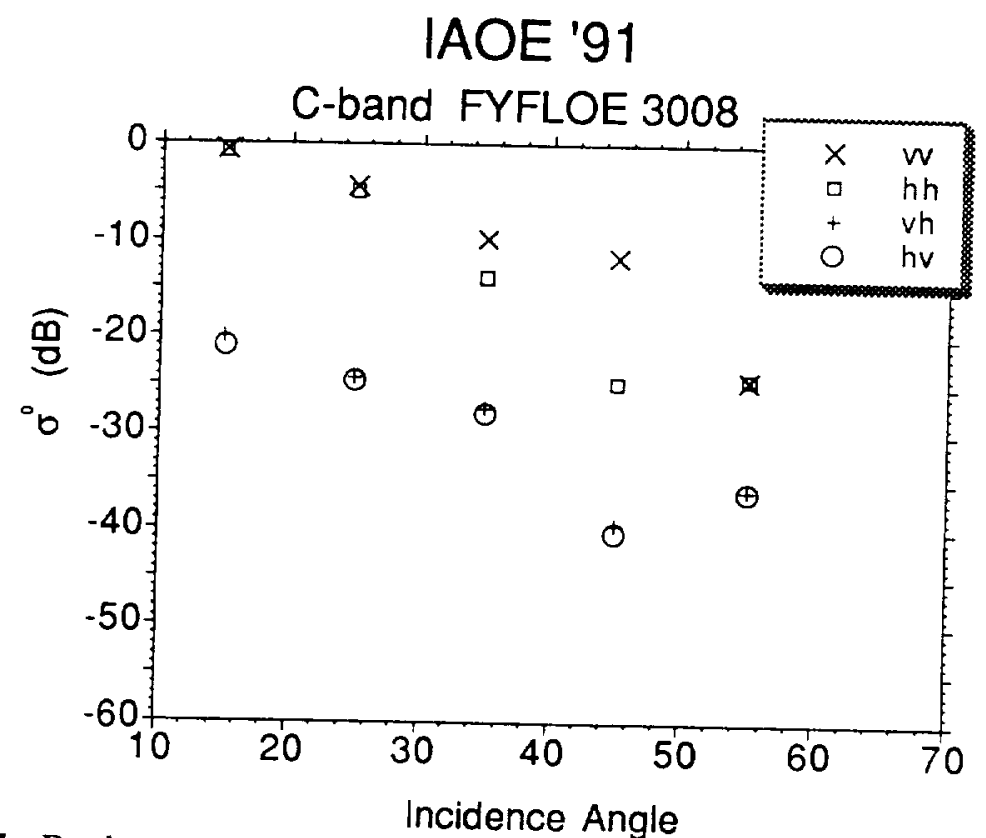

Figure 6.7. Backscatter coefficient for second-year sea ice. Measurements were performed on 30 August, 1991. 


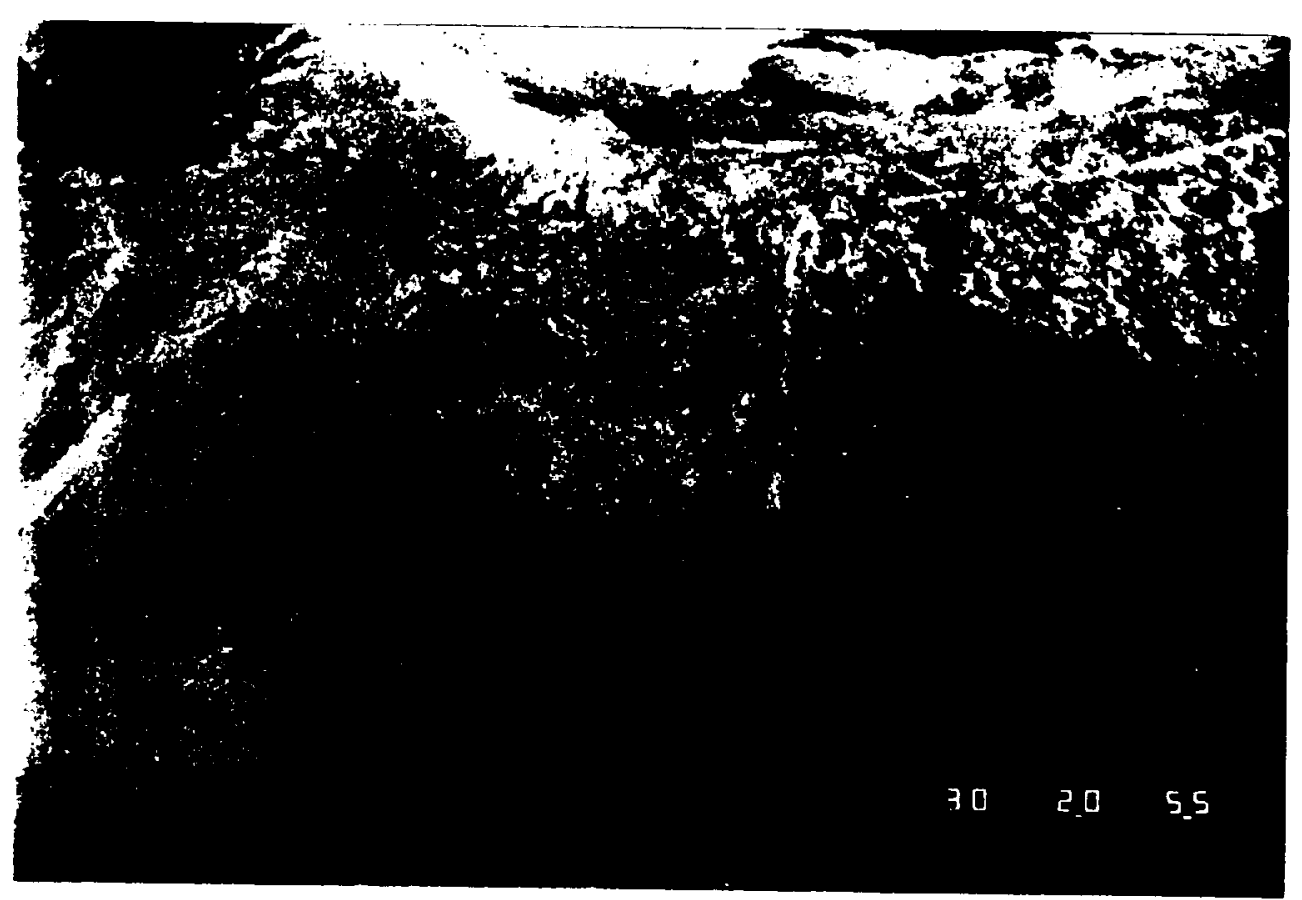

Photograph 6.4 Appearance of the scene for the data taken on the MY3008 multiyear sea ice floe. The backscatter data for this floe are shown in figure 6.8 below.

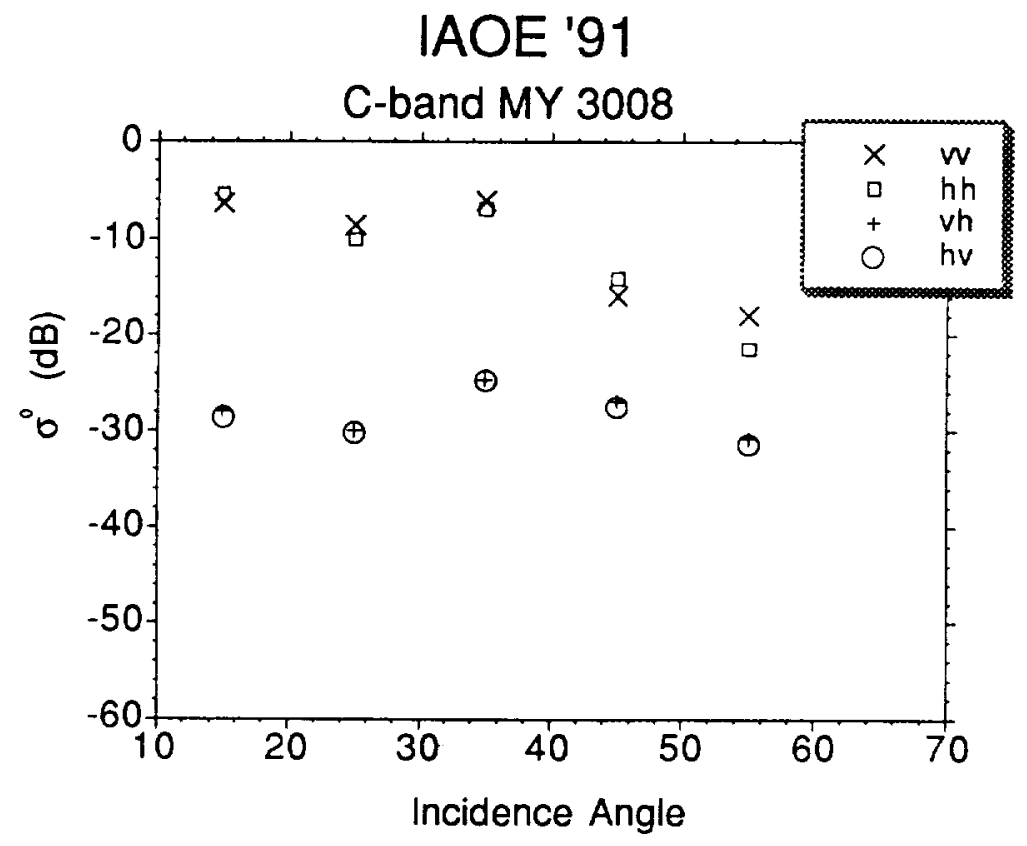

Figure 6.8. Backscatter coefficient for multiyear sea ice. Measurements were performed on 30 August, 1991. 


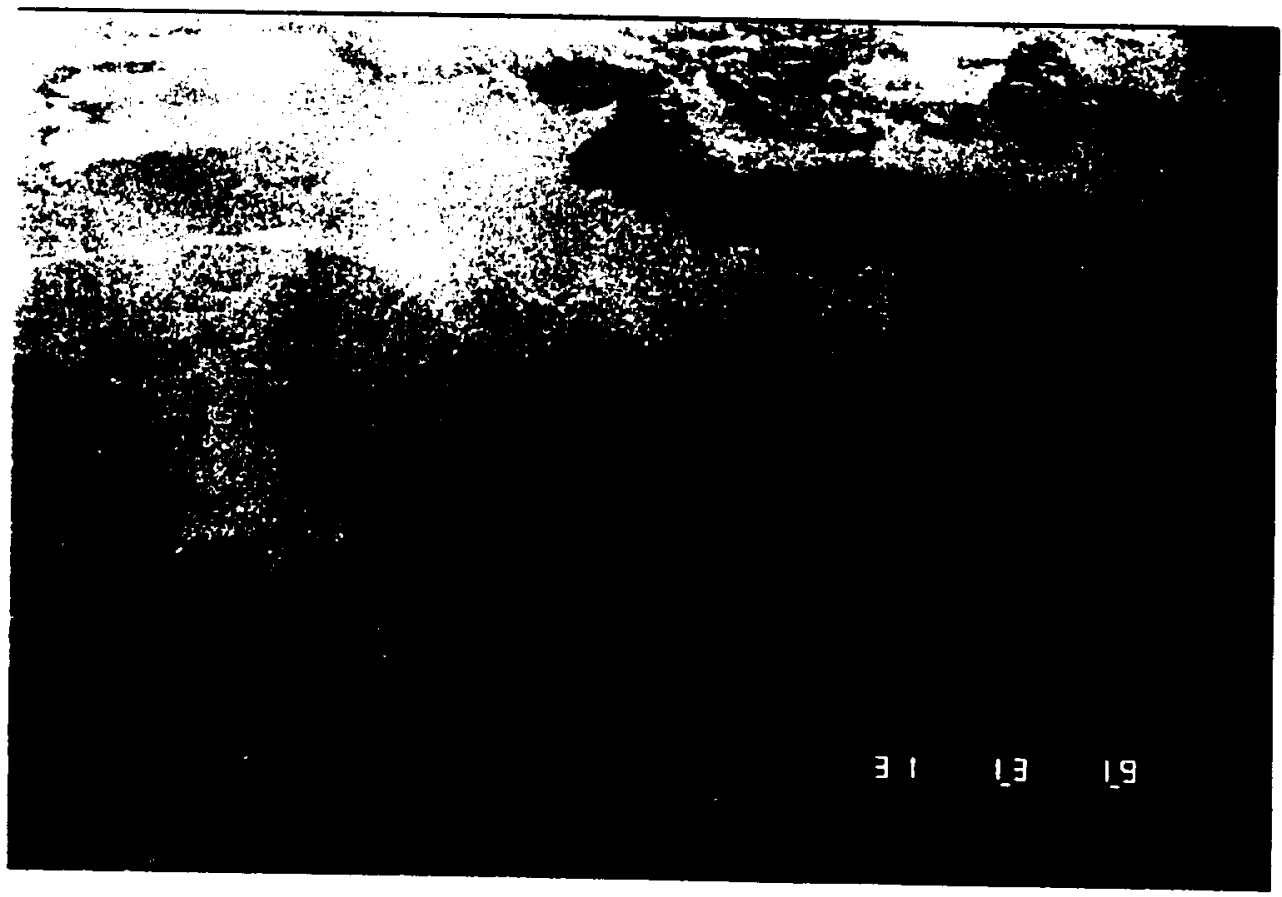

Photograph 6.5 Appearance of the scene for the data taken on the MY3108 multiyear sea ice floe. The backscatter from this floe is shown in figure 6.9.

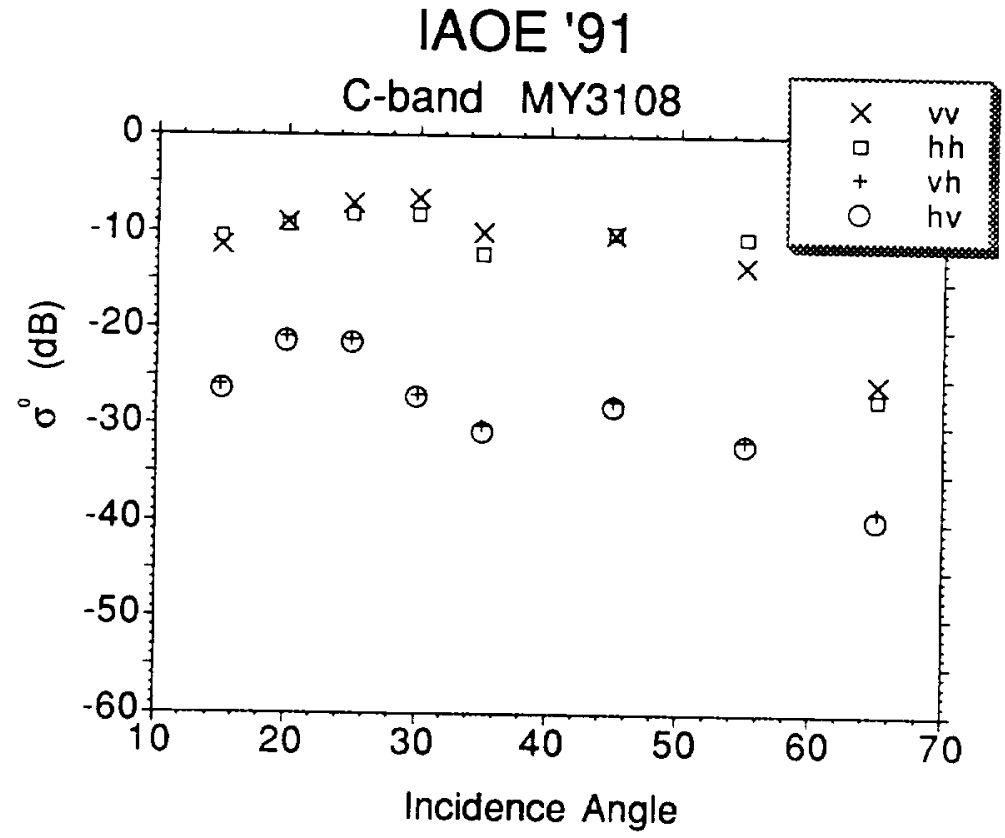

Figure 6.9. Backscatter coefficient for multiyear sea ice. Measurements were performed on 31 August, 1991. 


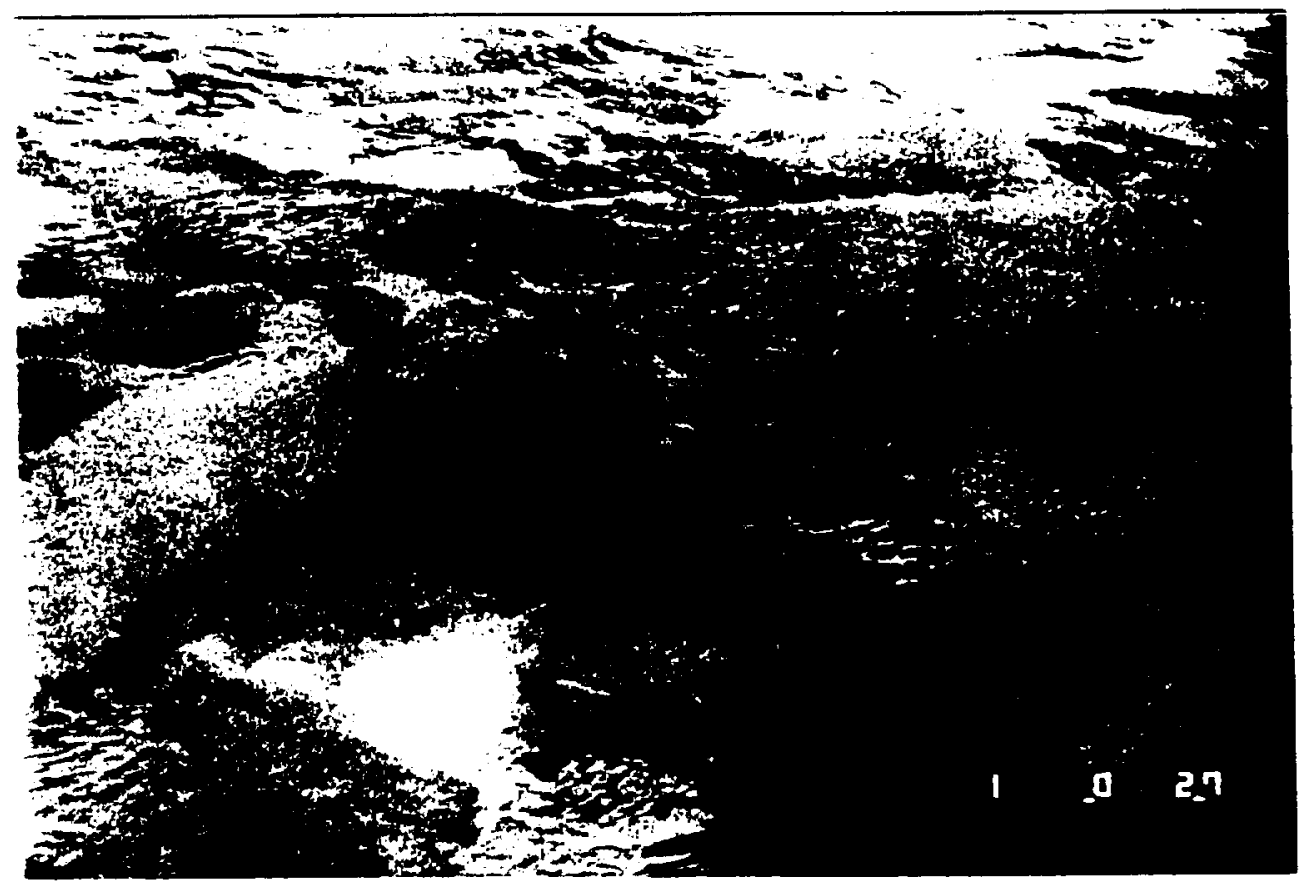

Photograph 6.6 Appearance of the scene for the data taken on the MY0109 multiyear sea ice floe. The backscatter data for this scene are plotted in figure 6.10.

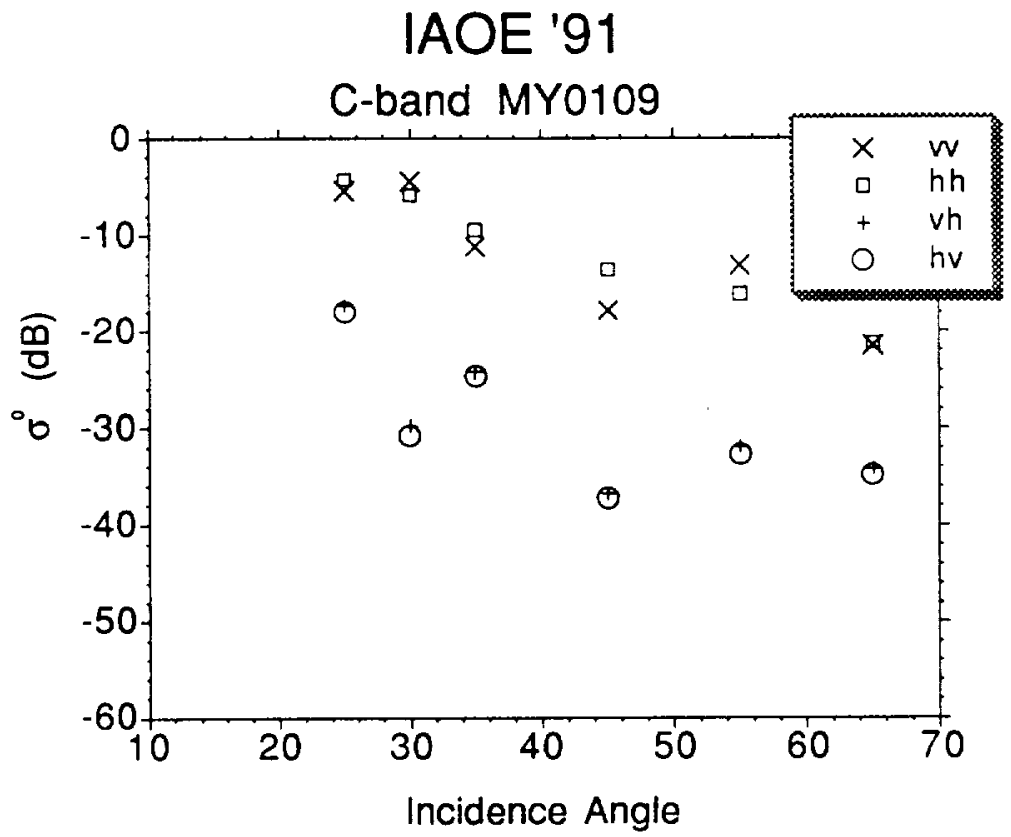

Figure 6.10. Backscatter coefficient for multiyear sea ice. Measurements were performed on 1 September, 1991. 


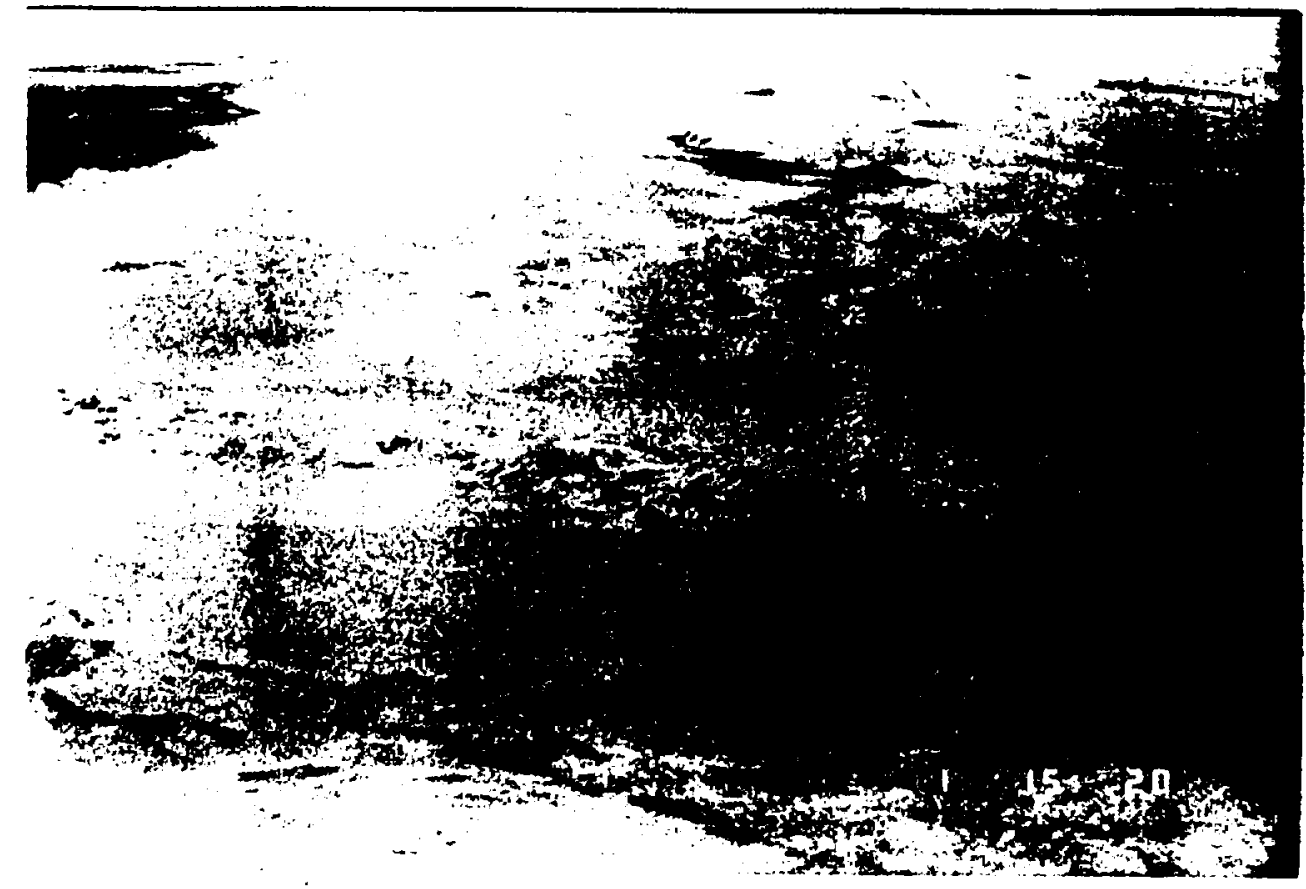

Photograph 6.7 Appearance of the scene for the data taken on the MY0109B multiyear sea ice floe. The backscatter data for this scene are plotted in

figure 6.11. The ridge is apparent in the backscatter data at $30^{\circ}$ and the melt ponds contribute for large incidence angles.

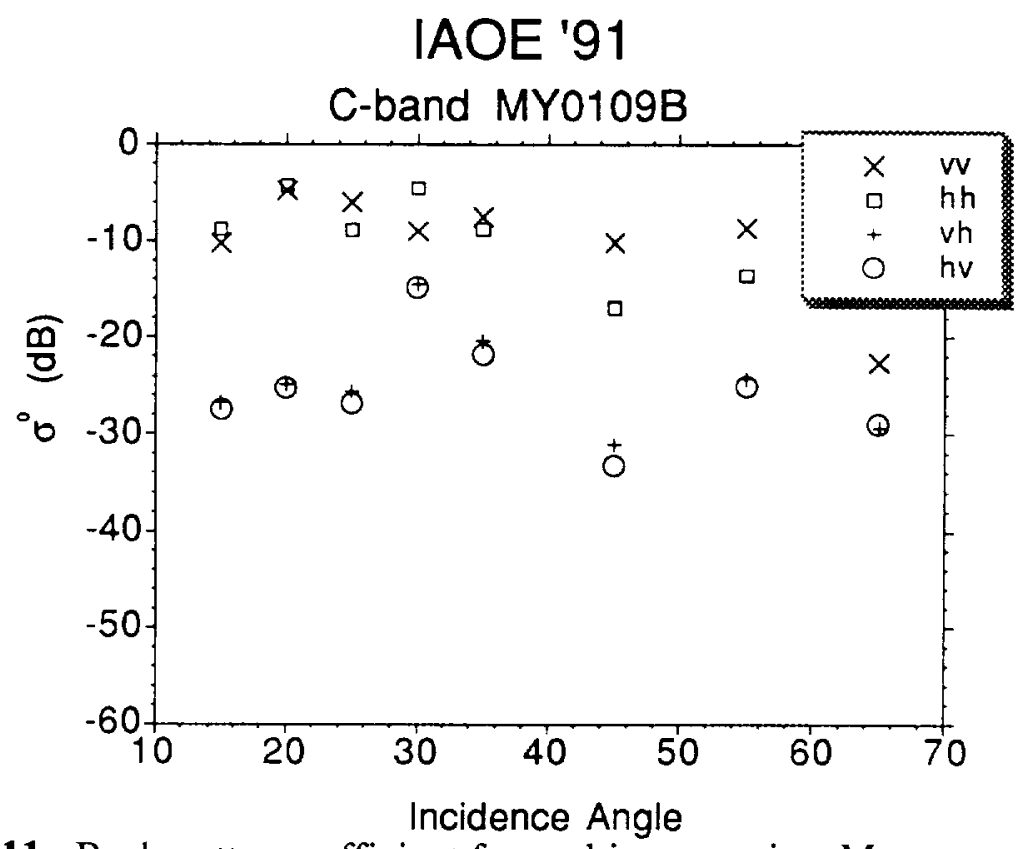

Figure 6.11. Backscatter coefficient for multiyear sea ice. Measurements were performed on 1 September, 1991. 

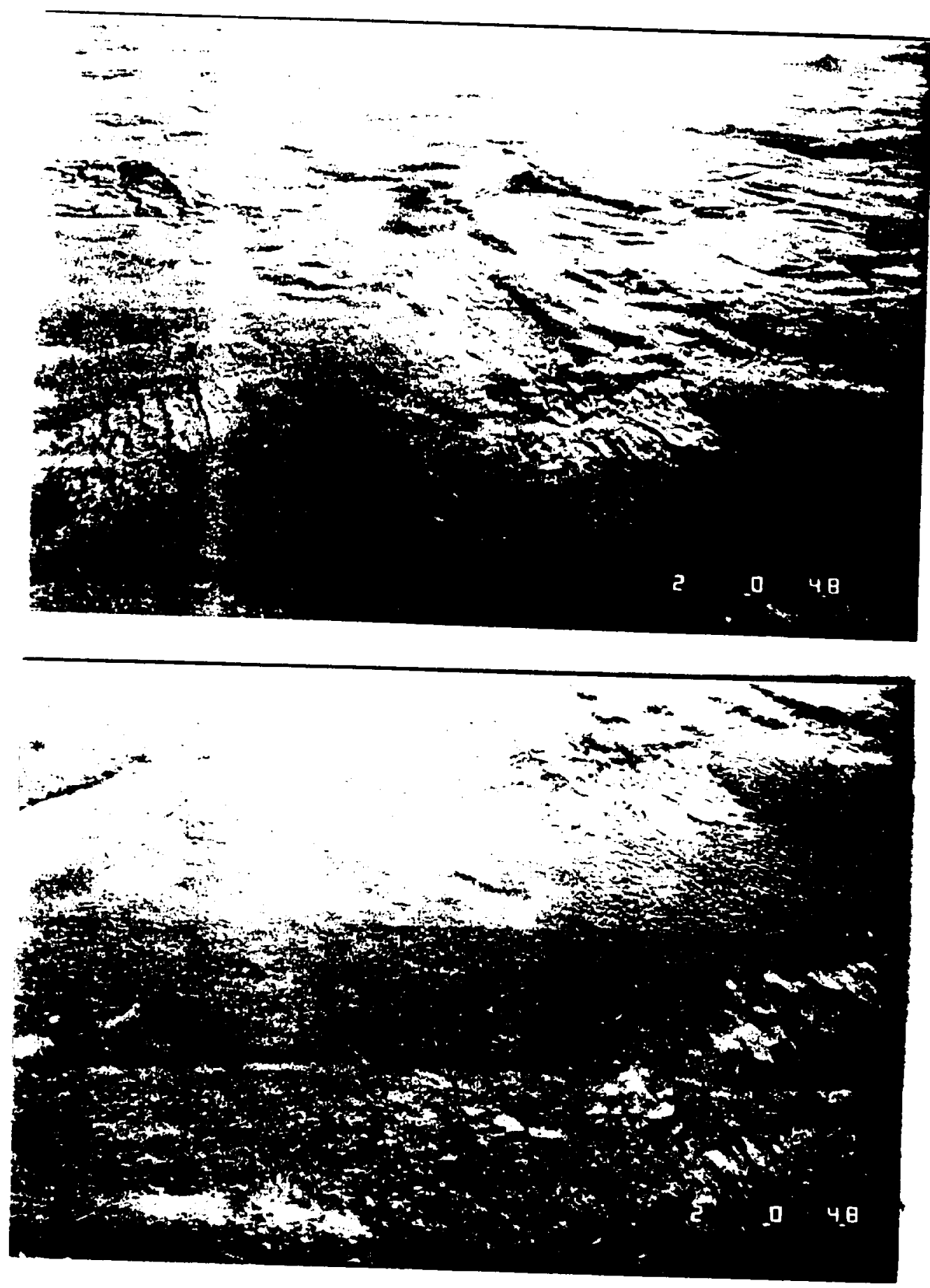

Photograph 6.8 Appearance of the scene for the data taken on the MY0209 multiyear sea ice floe, (a) low incidence angle view, and (b), high incidence angle view. The backscatter data for this scene are plotted in figure 6.12 . 


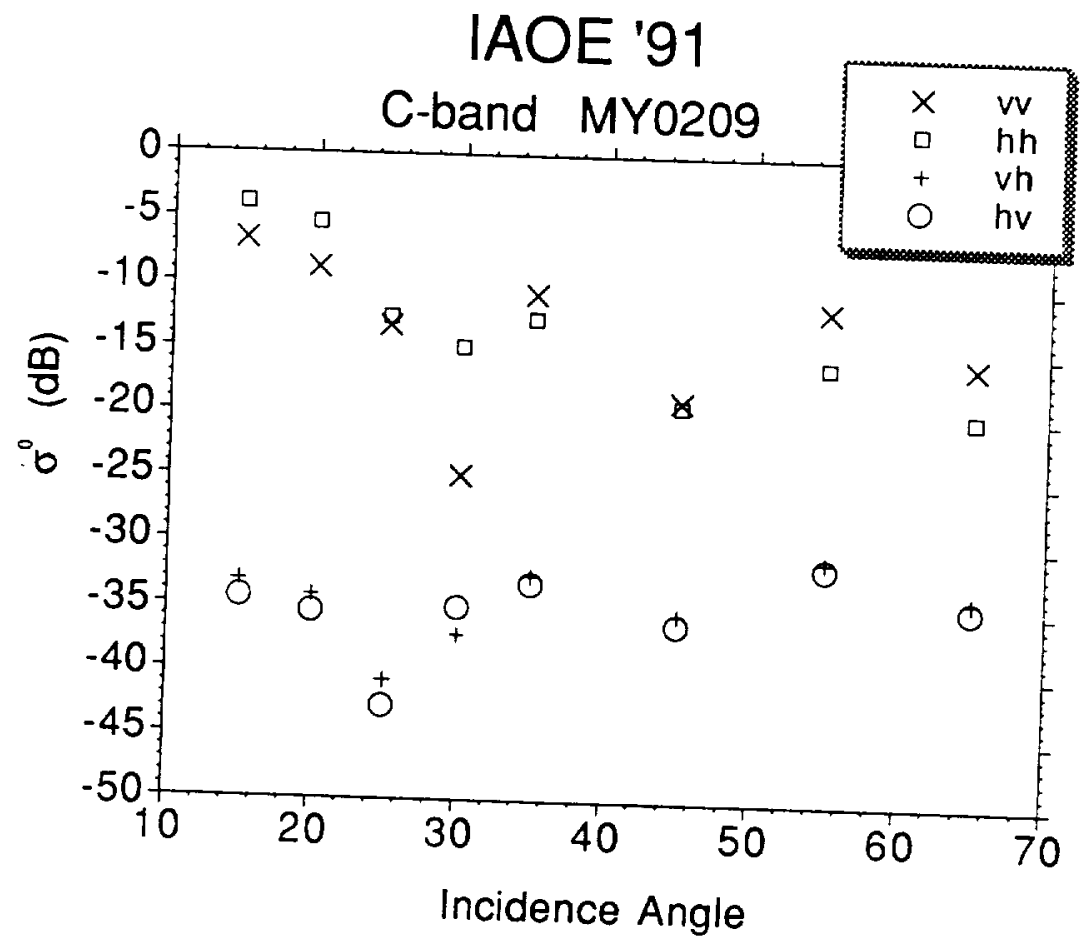

Figure 6.12. Backscatter coefficient for multiyear sea ice. Measurements were performed on 2 September, 1991. 


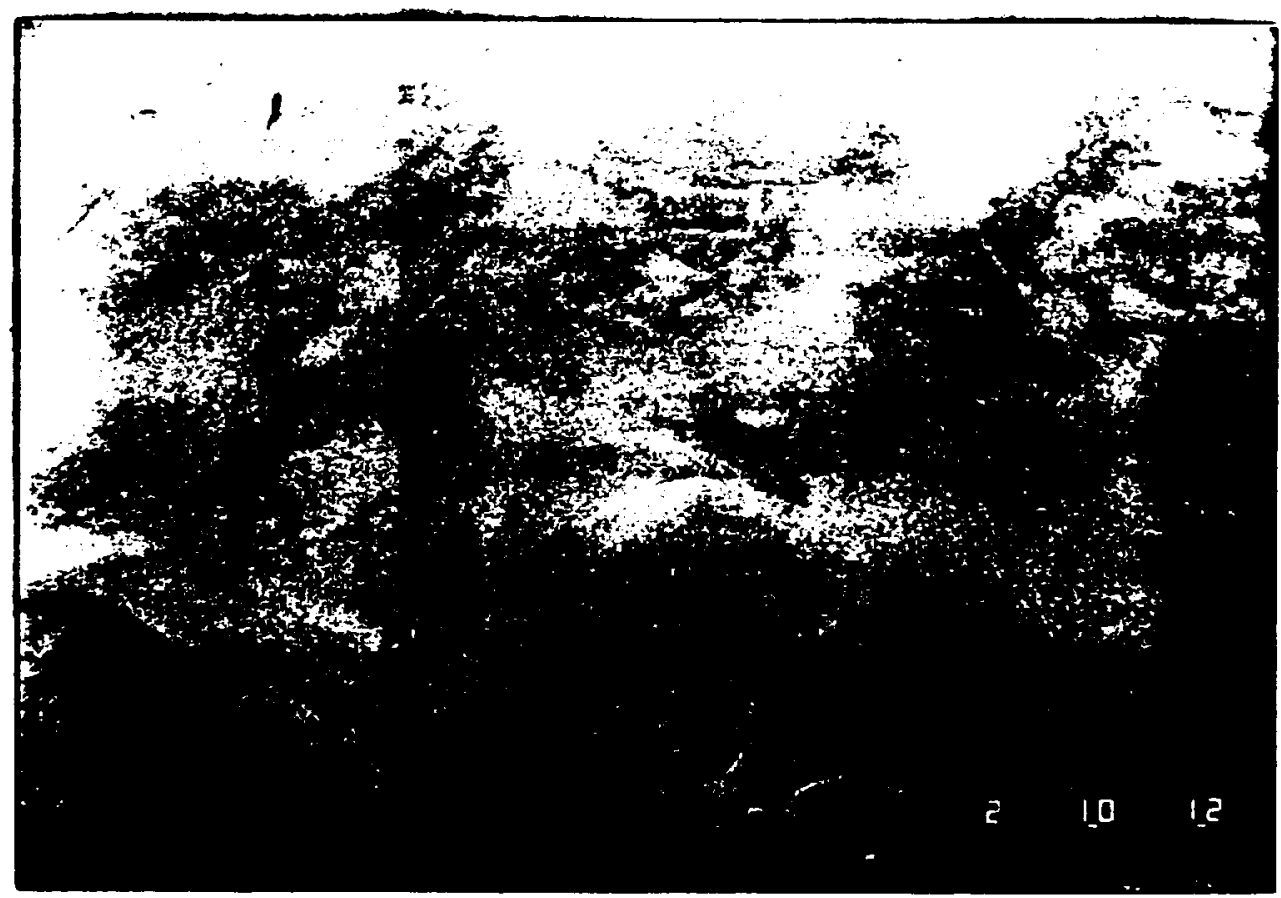

Photograph 6.9 Appearance of the scene for the data taken on the FY0209 secondyear sea ice floe. The backscatter data for this scene are plotted in figure 6.13.

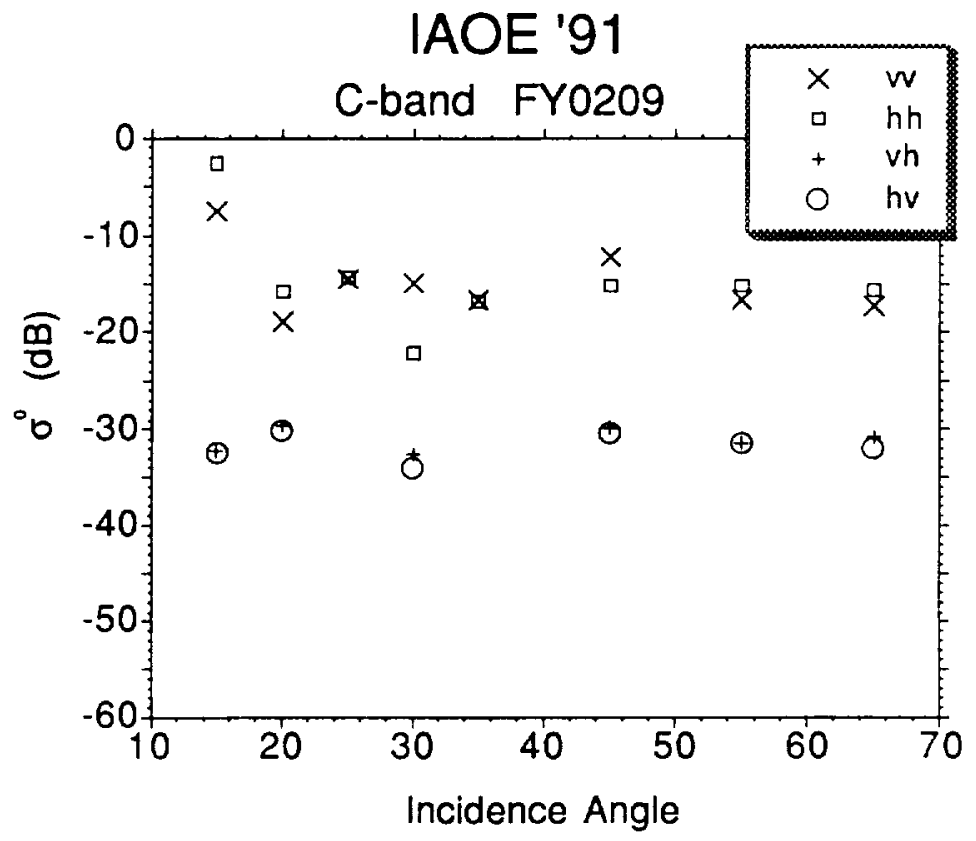

Figure 6.13. Backscatter coefficient for second-year sea ice. Measurements were performed on 2 September, 1991. 
These data show a trend of increasing backscatter coefficient as the temperatures dropped and the snow cover increased. The trend in the multiyear station data is plotted for incidence angles of $35^{\circ}$ and $25^{\circ}$ in figures 6.14 and 6.15. The corresponding plot of air temperature and snow depth is plotted in figure 6.16. A comparison of these two plots clearly shows the strong dependence of the backscatter on both the temperature and the depth of the snow. The apparent aberration on Julian day 242 (30 September) is due to the ridge in the radar footprint at $35^{\circ}$ as evidenced by photograph 6.4 and figure 6.8. As the temperature dropped from around freezing to $-5^{\circ} \mathrm{C}$, the co-polar (VV,HH) backscatter increased by about $18 \mathrm{~dB}$ and the cross-polarized (VH,HV) backscatter increased by nearly $30 \mathrm{~dB}$ at $35^{\circ}$ incidence angle. The increase in backscatter at $25^{\circ}$ incidence angle was somewhat less at $15 \mathrm{~dB}$ for co-polarized and 24 $\mathrm{dB}$ for the cross-polarized $\sigma^{\circ}$.

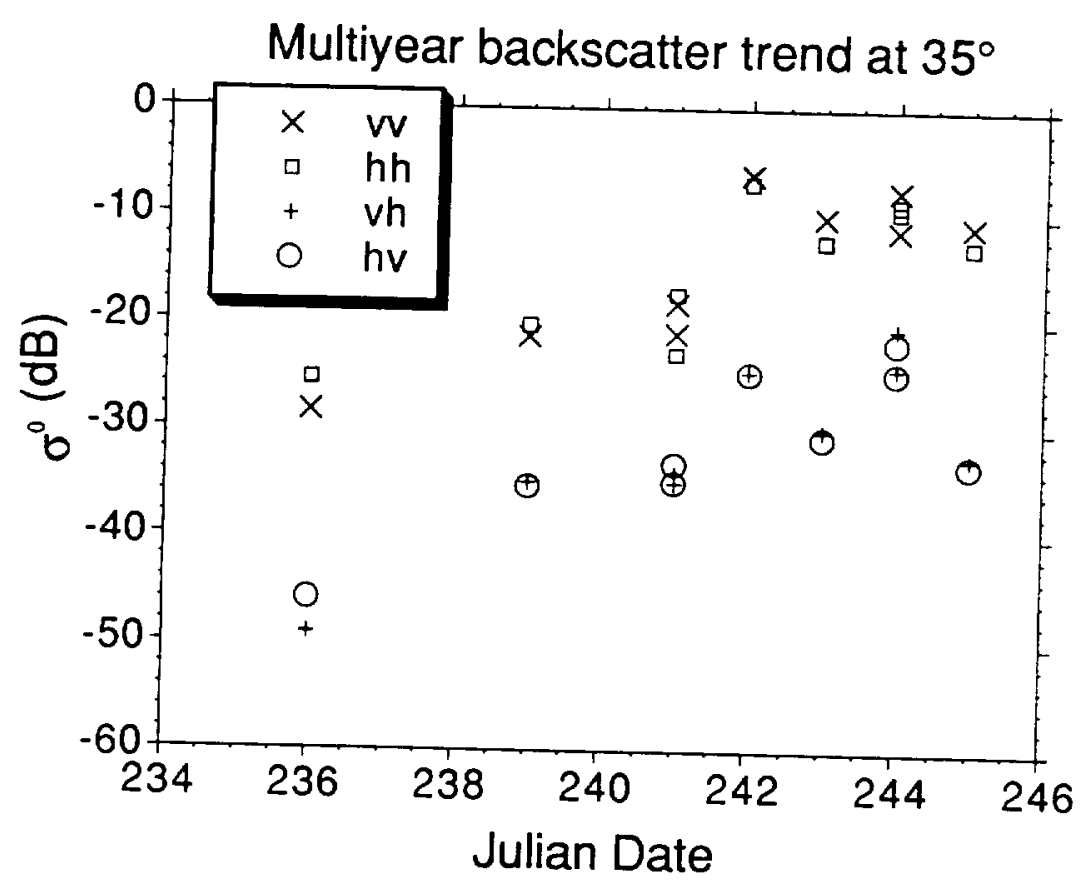

Figure 6.14. Trend of backscatter for $35^{\circ}$ incidence angle throughout the duration of IAOE' 91. 


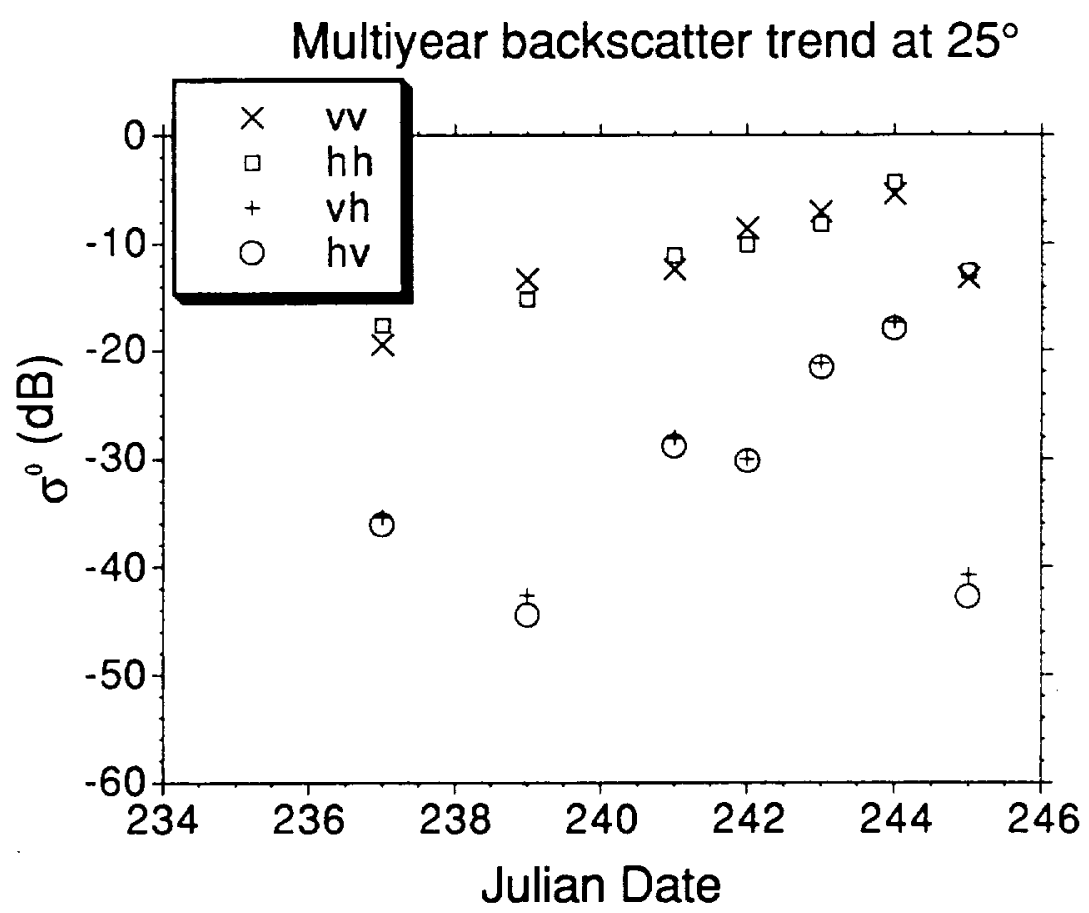

Figure 6.15. Trend of backscatter for $25^{\circ}$ incidence angle throughout the duration of IAOE'91.

The effect of air temperature on the backscatter is not direct as evidenced by the increase in backscatter from JD 236 to JD 241, while the air temperature only dropped slightly. After JD 241 the sudden decrease in temperature was accompanied by only a modest increase in backscatter. This may be due to the temperature measurements being just a single spot measurement. The change in temperature in the days and hours before the measurements were taken is presumably an important consideration. Unfortunately, this information is not available for this experiment since the station measurements were performed at stops along the expedition. The trend of increase in backscatter as the temperature (and amount of daily sunlight) decreases remains, although it may not be directly dependent on the temperature. 
Some of the local effects of the scenes examined are evident in these backscatter results. The backscatter from the multiyear floe MY2908, shown in figure 6.5, is the best example of the effect of melt ponds on the backscatter. The effects of the melt ponds seen in photograph 6.1(a) and (b) are observed in the marked decrease in backscatter at incidence angles of $30^{\circ}, 40^{\circ}$, and $55^{\circ}$. These angles are not considered in the trends plots of figures 6.14 and 6.15. This effectively removes the effect of the melt ponds from the study of backscatter increase during the fall freeze-up.

These data help to quantify the amount of increase in backscatter from multiyear ice that occurs during the seasonal change between the summer melt and the fall freeze-up. The physical mechanisms that may cause this increase could be the change in dielectric constant of the sea ice with temperature, the increase in backscatter due to the volume scatter of the snow cover, increased absorption by the snow layer with higher temperatures, or changes at the snow/ice interface due to the snow cover as the fall freeze-up commences. These changes may include a re-freezing of water on the ice surface or interaction between the sea ice and snow. Another hypothesis is that as melt ponds re-freeze there is an increase in volume scatter, causing an increase in large areaaveraged backscatter. This was observed from SEASAT scatterometer data at Ku band [Drinkwater and Carsey, 1991]. The data shown here are not large-area averages, but are taken over small areas. The effects of the melt ponds are seen in the individual measurements, (figure $6.5,30^{\circ}$ incidence angle, for example), but are removed when considering the general trend of figures 6.14 and 6.15 .

Since the onset of colder temperatures and the increase in snow cover are correlated, precisely determining the mechanism for the increase in backscatter from this 
experiment alone is difficult. However, the large increase in backscatter observed with decreasing temperature cannot be explained by the presence of snow cover alone. As discussed later (section 7) the increase in backscatter with increased temperature is the change of scattering mechanism from that of surface scattering to volume scattering.

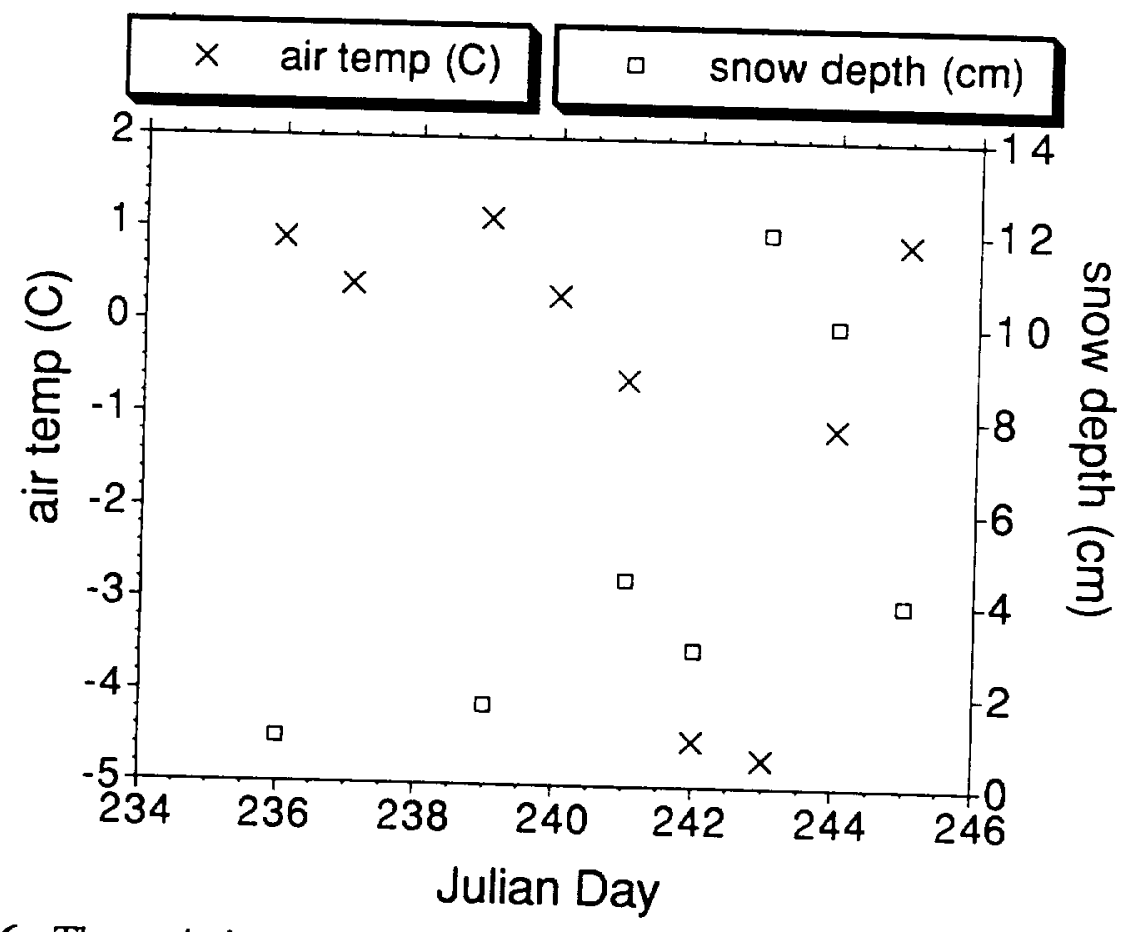

Figure 6.16. The variation of the air temperature and snow depths measured during IAOE'91, corresponding to the backscatter measurements shown in figures 6.14 and 6.15 .

\subsection{Transit data results}

While the ship was in transit, radar backscatter measurements were performed at a fixed angle of incidence. This angle was set to $35^{\circ}$ for the majority of the measurements. This angle was selected to be as close as possible to that of the ERS-1 SyntheticAperture Radar (SAR) without the measurements being affected by the ship's effect on the sea ice. Taking data while the ship was in transit allowed a wide variety of ice types to be investigated. These included multiyear sea ice as well as young ice types such as 
dark nilas, white nilas, pancake and slush. The transit data also complemented the station data in documenting the effect of the fall freeze-up as mentioned previously in this section.

\subsubsection{First-/Second-year and multiyear transit data}

A large number of measurements of backscatter from first-/second-year and multiyear sea ice floes were performed as the ship was in transit. These data were acquired under a variety of conditions and were taken with coincident passive microwave data by MWG. The majority of these data may be useful in planned future comparison with these passive microwave data.

The entire transit data set at $35^{\circ}$ incidence angle for first-year sea ice was plotted as a distribution in figure 6.17. This demonstrates the overall nature of first-year sea ice backscatter during late August and early September in the central Arctic Ocean. In this figure the center bar for each polarization represents the median value of all the measurements. The top and bottom of each filled box represent the $\pm 25 \%$ points in the distribution (from the mean), and the extended bars represent the $\pm 45 \%$ values (from the mean). The median value is $-22 \mathrm{~dB}$ for $\mathrm{VV}$ polarization and $-23 \mathrm{~dB}$ for $\mathrm{HH}$ polarization. The cross-polarized $\sigma^{\circ}$ values are slightly less than $-40 \mathrm{~dB}$. A similar figure for multiyear sea ice is shown in figure 6.18. Here the co-polar backscatter is slightly higher with a median value of $-20 \mathrm{~dB}$ and $-22 \mathrm{~dB}$, for $\mathrm{VV}$ and $\mathrm{HH} \sigma^{\circ}$, respectively. The cross-polarized $\sigma^{\circ}$ for the multiyear ice measured is about $-40 \mathrm{~dB}$. 


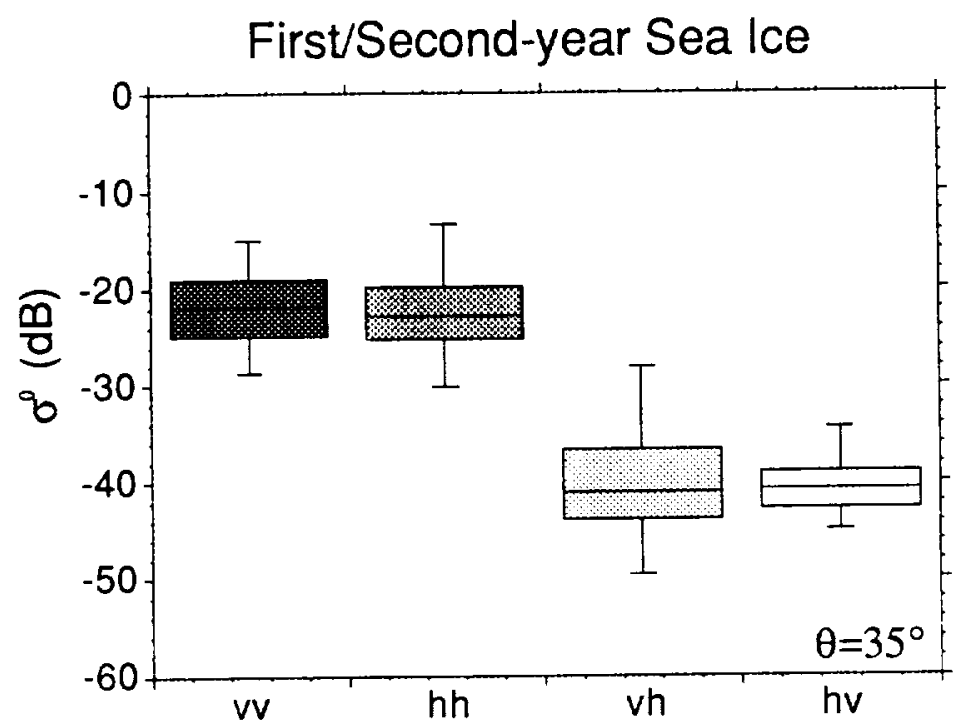

Figure 6.17. Distribution of first/second-year sea ice backscatter for transit mode measurements during IAOE'91.

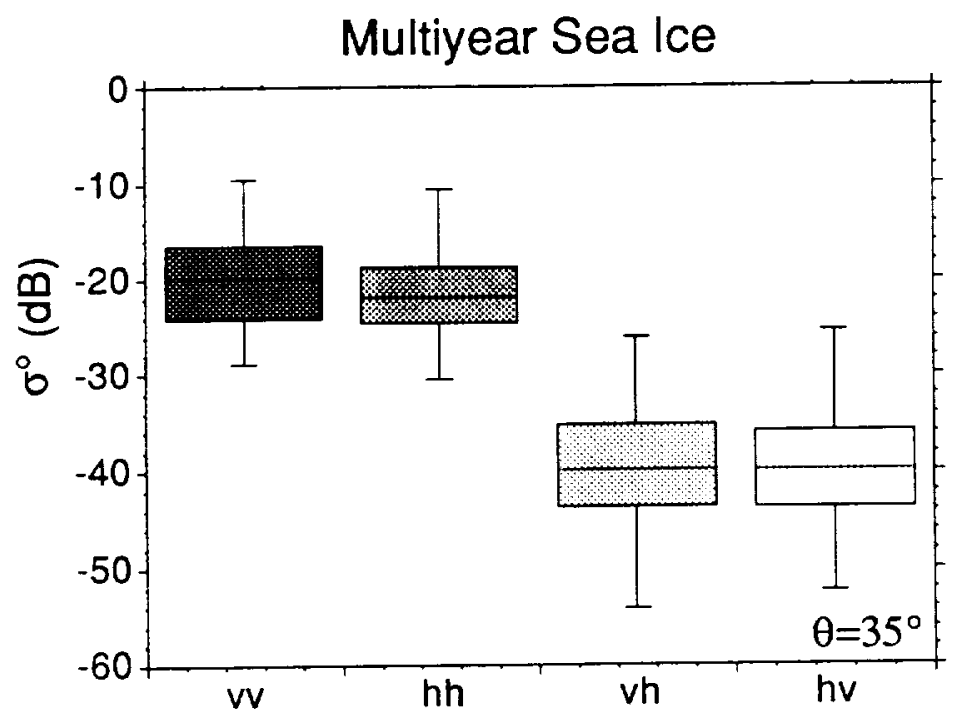

Figure 6.18. Distribution of multiyear sea ice backscatter for transit mode measurements during IAOE' 91. 
The similarity between the multiyear and first-/second-year measurements is due to the first-year ice going through the summer melt. In fact, at the onset of the freeze-up this is considered second-year sea ice, which is similar enough to multiyear ice that it is not distinguishable at $35^{\circ}$ incidence angle. The angular variation in the station data measurements, though, reflects the difference between these ice types as shown in figures 6.7 and 6.8 .

\subsubsection{Young sea ice types}

The backscatter coefficients for several young sea ice types were measured during the expedition. These types included white nilas, dark nilas, and grease and frazil sea ice. The resulting spread of these data are shown in the figure 6.19. The first plot shows the spread of the data for the four linear polarizations for all the young ice types combined. For the two-week cruise the median value for thin ice types at $35^{\circ}$ was -25 $\mathrm{dB}$ for $\mathrm{VV}$ polarization and $-26 \mathrm{~dB}$ for $\mathrm{HH}$ polarization, with the majority of the measurements falling in the range of -36 to $-19 \mathrm{~dB}$ (co-polarized). The cross-polarized measurements varied in the range -55 to $-45 \mathrm{~dB}$. The thin ice types were broken down into their various classes such as grease and frazil, white nilas and dark nilas. These distributions are shown in succeeding plots of figure 6.19. 


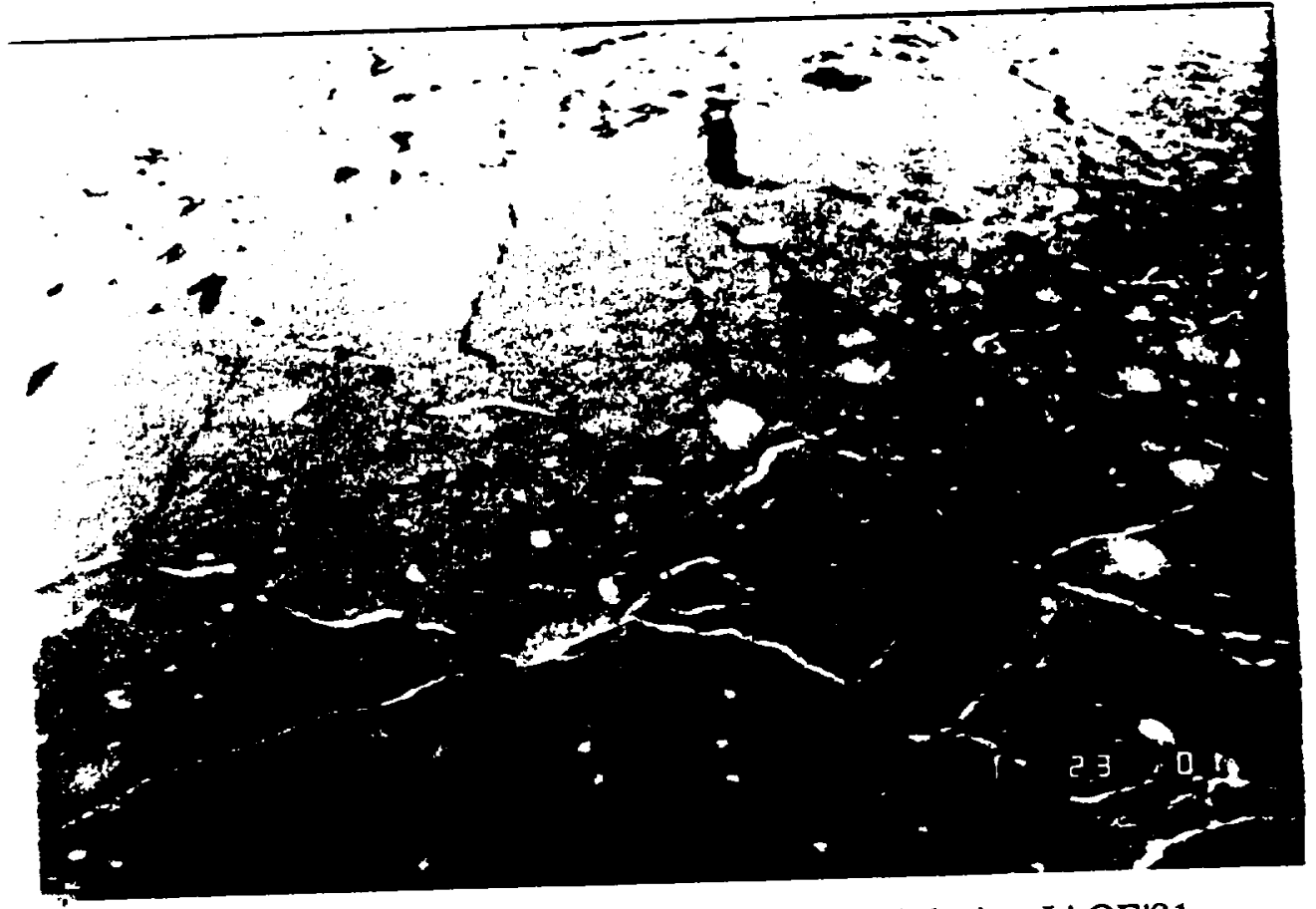

Photograph 6.10 White nilas sea ice observed during IAOE'91.

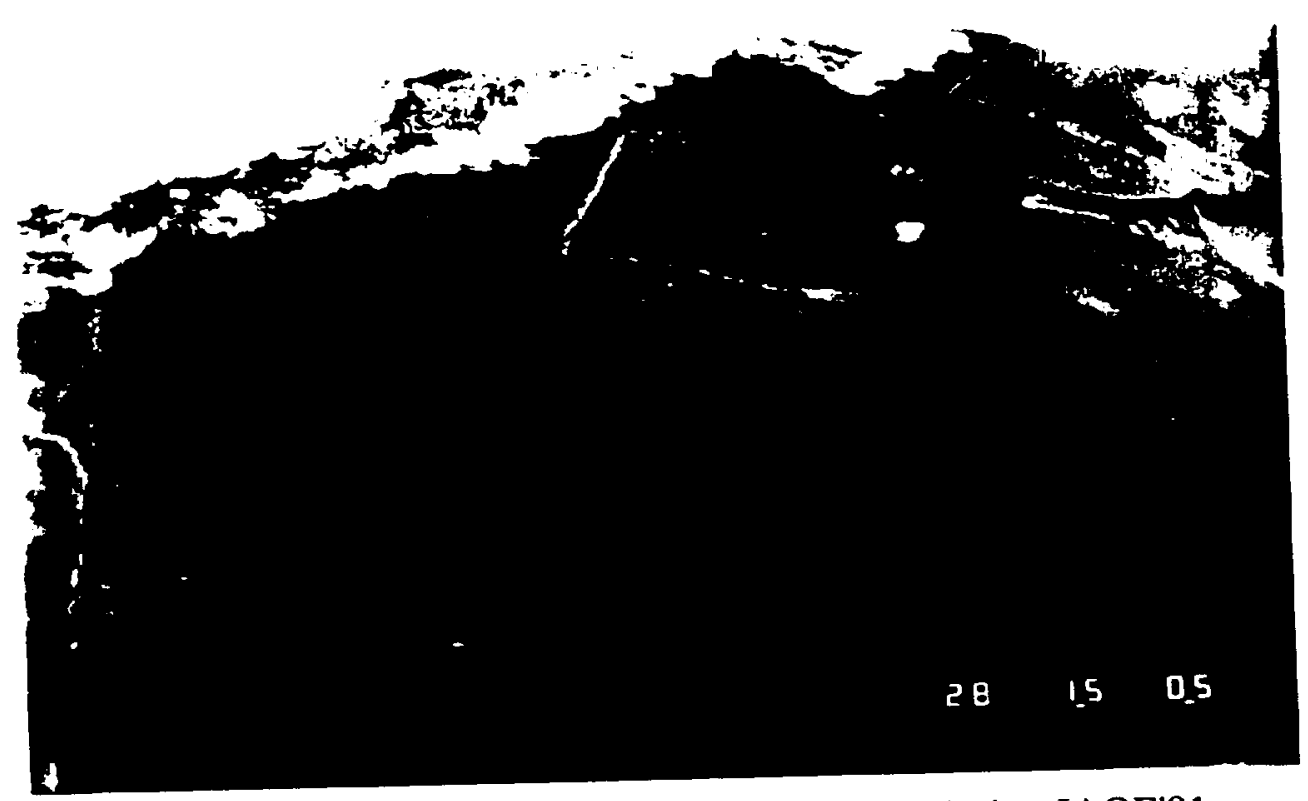

Photograph 6.11 Dark nilas sea ice observed during IAOE'91. 


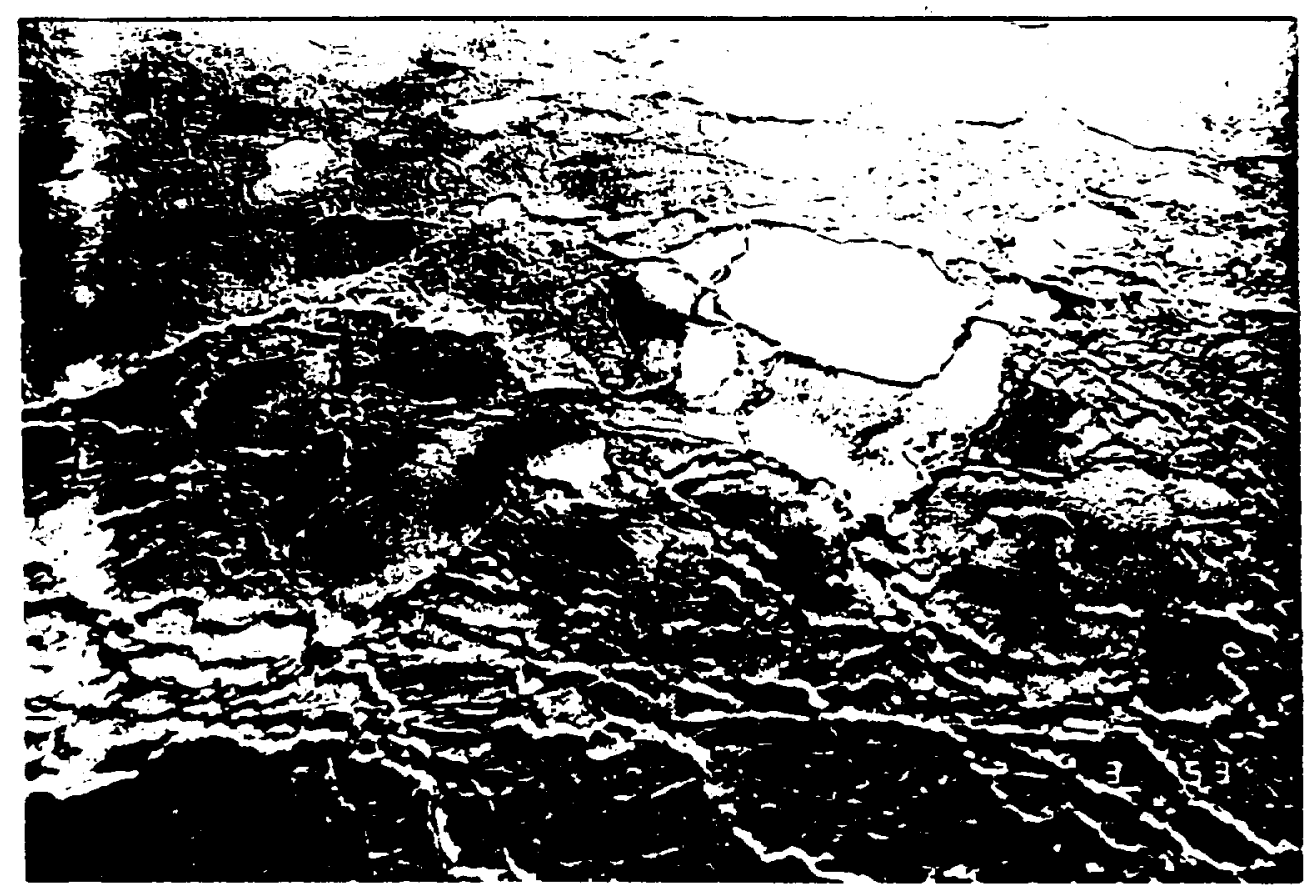

Photograph 6.12 White nilas/pancake sea ice observed during IAOE'91. 

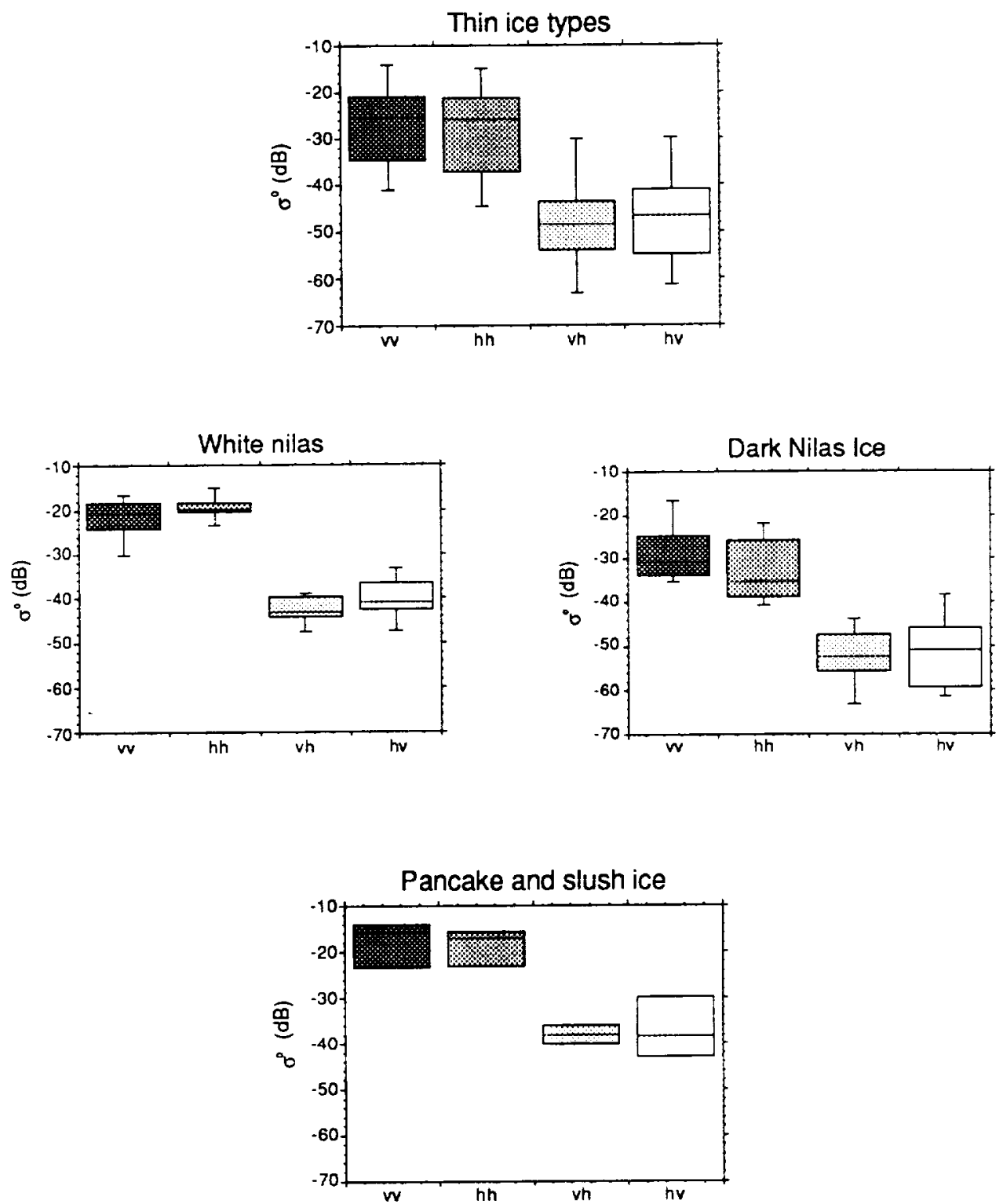

Figure 6.19. Young sea ice distributions measured during IAOE' 91 . The center line indicates the median value for the given polarization. The top and bottom of each of the boxes indicate the $\pm 25 \%$ of the distribution and the extended line (when shown) demonstrates the $\pm 45 \%$ values for the distribution. 
The young sea ice signatures measured during IAOE'91 give insight into the capability for observing these ice types with radar. The importance of young sea ice is that sea ice cover modulates the heat flux between the ocean and the Arctic air. It also causes a distinct change in albedo of the surface. Young sea ice growth is responsible for the change in sea ice cover during the fall freeze-up and into the winter. These results indicate that it may not be possible to observe young dark nilas sea ice from spaceborne sensors such as ERS-1.

ERS-1 operates at $\mathrm{C}$ band with VV polarization and is capable of measuring backscatter coefficients as low as about $-27 \mathrm{~dB}$. These data show that it is unlikely ERS-1 can measure either dark nilas or grease and frazil ice, but is capable of observing white nilas ice. It should be kept in mind that these measurements were performed at $35^{\circ}$, whereas ERS-1 operates around $23^{\circ}$. For very smooth ice grown at the CRRELEX ' 90 experiments the decrease in backscatter coefficient from $20^{\circ}$ to $35^{\circ}$ was only 6 to $8 \mathrm{~dB}$. Actual angular variations for the IAOE'91 expedition seldom changed by more than 10 $\mathrm{dB}$ over the entire angular range measured $\left(20^{\circ}\right.$ to $\left.55^{\circ}\right)$. 


\section{Comparison to Scattering Theory}

To investigate the causes for the increase in backscatter observed during the fall freezeup, the measurements were compared with simple volume scattering theory based on the Rayleigh model, described in this section. The contribution of the snow cover to the backscatter coefficient during the onset of the fall season is investigated here. The effect of the absorption of the snow is also investigated as a possible contributor to the effect seen during the fall freeze-up.

7.1 Rayleigh model for volume scattering from a snow layer during IAOE'91

The Rayleigh model has been used effectively to model the backscatter from dry snow [Ulaby, et al., 1982]. This model assumes that the particles are spheres with radii that are small with respect to wavelength. Assuming that the scattering from each sphere is independent, the backscatter from a dry snow layer of depth $\mathrm{d}$ is given as,

$$
\sigma_{\text {snow }}^{0}=\frac{\sigma_{v} \cos \theta}{2 \kappa_{e}}\left(1-\mathrm{e}^{-2 \mathrm{~d} \kappa_{\mathrm{e}} \sec \theta}\right)
$$

where $\theta$ is the incidence angle and the scattering cross section is given as [Kong,

1990],

$$
\sigma_{\mathrm{v}}=\frac{8 \pi\left(\varepsilon_{\mathrm{s}}-\varepsilon\right)^{2}}{3\left(\varepsilon_{\mathrm{s}}+2 \varepsilon\right)^{2}}
$$

The extinction coefficient, $\kappa_{\mathrm{e}}$ is given by

$$
\kappa_{c}=2 R_{v} r^{3} k_{0}^{4} \frac{\left(\varepsilon_{s}-\varepsilon\right)^{2}}{\left(\varepsilon_{s}+2 \varepsilon\right)^{2}},
$$

where $k_{0}$ is the wave number, $\varepsilon_{S}$ is the permittivity of the ice particles that comprise the snow, and $\varepsilon$ is the permittivity of free space. The average radius of the snow is $r$ and the volume density of the snow is $R_{V}$. 
The Rayleigh model for scattering due to a dry snow layer was computed for the cases listed in table 5.1. These were calculated for the following multiyear floes: MY2908, MY3008, MY3108, MY0109B, and FY0209. These correspond to Julian days 241 through 245 and are cases in which dry snow ( $<1 \%$ wetness) was observed. These results are shown in figure 7.1 .

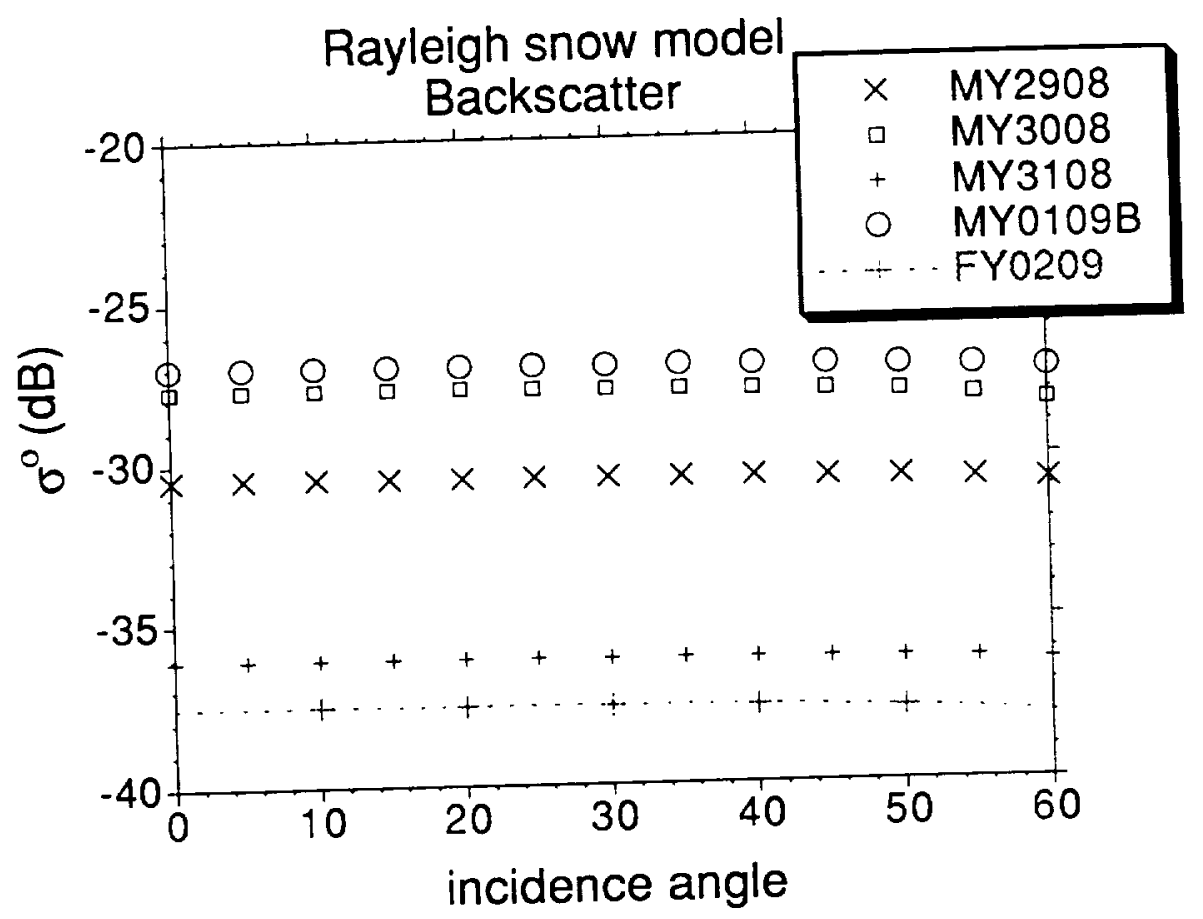

Figure 7.1 Results of Rayleigh backscatter model for snow cover observed during IAOE'91. These demonstrate that the backscatter from the snow does not cause the dramatic increase in $\sigma^{\circ}$ observed during the fall freeze-up.

These model results show that the backscatter due to snow volume scattering at $\mathrm{C}$ band cannot account for the increase in backscatter observed during IAOE'91. In each case the backscatter measured is at least $10 \mathrm{~dB}$ higher than the theoretical snow volume backscatter. The primary factor for the variation among these computations is due to the snow depth measurement. The MY0109B floe had $10 \mathrm{~cm}$ of snow, whereas the 
FY0209 floe had $4 \mathrm{~cm}$ of snow. This results in a 10-dB difference between the computation of snow volume backscatter for these two cases even though the grain size and density are nearly the same.

\subsection{Effect of wet snow on backscatter}

The loss due to wet snow may play a large role in the backscatter of snow-covered sea ice. It has been shown [Hallikainen, 1986 and 1992] that for snow of $2 \%$ wetness by volume the loss can be as much as $10 \mathrm{~dB} /$ meter depending on the frequency used. The attenuation in a lossy medium in terms of its dielectric constant $\left(\varepsilon_{\Gamma}=\varepsilon^{\prime}-\mathrm{j} \varepsilon "\right)$ is given by [Ulaby, et al., 1982] as,

$$
\alpha=\frac{2 \pi}{\lambda_{0}} \sqrt{\frac{1}{2} \varepsilon^{\prime}\left[\sqrt{1+\left(\frac{\varepsilon^{\prime \prime}}{\varepsilon^{\prime}}\right)^{2}}-1\right]} .
$$

The power absorption coefficient is given by

$$
\kappa_{\mathrm{a}}=8.686 \alpha \quad(\mathrm{dB} / \mathrm{m})
$$

For a medium described by $\varepsilon_{\mathrm{r}}$ it has been shown that an empirical model for wet snow, called the Debye-like model, fits measured dielectric measurements well [Hallikainen, 1986]. This model is described by the empirical equations,

$$
\varepsilon^{\prime}=A+\frac{0.073 \mathrm{~m}^{1.31}}{1+\left(\frac{\mathrm{f}}{\mathrm{f}_{0}}\right)^{2}}
$$

and

$$
\varepsilon^{\prime \prime}=\frac{0.073\left(\frac{f}{f_{0}}\right) \mathrm{m}^{1.31}}{1+\left(\frac{f}{f_{0}}\right)^{2}}
$$

where

$$
\mathrm{A}=1+1.83 \rho+0.02 \mathrm{~m}^{1.015}
$$


In the above equations $\rho$ is the dry snow density, $\mathrm{f}_{0}$ is $9.07 \mathrm{GHz}, \mathrm{m}$ is the volume fraction of snow, and $f$ is the frequency of interest in the calculation. The measured $\rho$ for the various snow covers encountered in IAOE'91 (table 6.1) were used to calculate estimates of $\varepsilon "$. These were then used in equations 7.5 and 7.6 to obtain estimates of the power absorption due to the snow cover. The total loss due to absorption through the wet snow cover is then twice snow depth times the power absorption coefficient,

$$
\operatorname{Loss}_{w \mathbf{s}}=2 \kappa_{\mathrm{e}} \mathrm{d}_{\mathrm{s}} \text {. }
$$

If the path length through the snow is adjusted for the angle of incidence, $\theta$, the result is multiplied by $\sec \theta$. This was used to calculate the estimated loss due to the snow cover for the measurements taken during IAOE' 91 at $25^{\circ}$ and $35^{\circ}$. These results are shown in table 7.1.

Table 7.1 Total estimated losses due to absorption of wet snow for IAOE'91

\begin{tabular}{|c|c|c|c|}
\hline \hline Station & $\varepsilon^{\prime \prime}$ from $(7.7 \mathrm{~b})$ & Loss at $25^{\circ}(\mathrm{dB})$ & Loss at $35^{\circ}(\mathrm{dB})$ \\
\hline FY2208 & 0.176 & 0.65 & 0.71 \\
\hline MY2408 & 0.05 & 0.47 & 0.52 \\
\hline MY2708 & 0.03 & 0.13 & 0.14 \\
\hline MY2908 & 0.014 & 0.59 & 0.65 \\
\hline MY3008 & 0.007 & 0.19 & 0.21 \\
\hline MY3108 & 0.004 & 0.45 & 0.50 \\
\hline MY0109B & 0.007 & 0.65 & 0.72 \\
\hline FY0209 & 0.012 & 4.3 & 4.8 \\
\hline
\end{tabular}

For the two cases where $\varepsilon "$ was computed to be 0.007 , the snow wetness was not measured, so $0.3 \%$ by volume was assumed. These data demonstrate that in all cases, 
except on 2 September (Julian day 245), the absorption loss due to the snow cover was negligible. It would require $10 \mathrm{~cm}$ of $10 \%$ wet snow to cause a $20-\mathrm{dB}$ loss according to this model. The loss through wet snow before freeze-up and the re-freezing of the snow layer does not account for the increase in backscatter measured during the fall freeze-up

These comparisons to simple scattering models demonstrate that the most likely causes of the increase in C-band backscatter during the fall freeze-up are not due to scattering or absorption effects of the snow. A possible reason for the increase in backscatter with decrease in temperature is volume scatter from air pockets embedded in the ice. When the air temperatures are near freezing the ice surface may be wet. The presence of moisture on the ice may block the volume scatter from the ice. Further study of the effect of the interaction between sea ice and snow on backscatter is needed. 


\section{Summary of IAOE'91 Results}

C-band radar backscatter measurements of sea ice during the fall freeze-up were made during IAOE'91 from aboard the US Coast Guard icebreaker Polar Star. These measurements showed that the co-polarized backscatter increased by $15-20 \mathrm{~dB}$ at incidence angles of $25^{\circ}$ and $35^{\circ}$ during the freeze-up. The cross-polarized measurements also showed the same dramatic increase as the temperatures dropped. These measurements were carefully calibrated and coherent noise sources in the system were removed using a simple noise reduction technique.

The results shown here demonstrate that the co-polar scattering coefficient from multiyear sea ice was $5 \mathrm{~dB}$ higher than that from first-year ice at incidence angles greater than $40^{\circ}$. The backscatter values for first-/second-year sea ice and multiyear sea ice are very similar at the onset of the fall freeze-up over the range of incidence angles from $20^{\circ}$ to $45^{\circ}$. This is due to the fact that the first-year sea ice has undergone one season of summer melt and is becoming more similar to multiyear ice. At the time of the fall freeze-up the first-year ice actually becomes second-year ice. The similarity may also be due to moisture in the upper snow-ice layers of the sea ice.

Four possible causes of the dramatic increase in the backscatter observed during the fall freeze-up are investigated here. Three of these were shown not to be the primary cause for the dramatic change in backscatter. The increase in volume scatter due to the snow accumulation was found to be insignificant by use of the Rayleigh model. The effect of absorption loss in wet snow also was considered a likely cause for the decrease in backscatter with increase in temperature. This effect was also shown to be negligible 
for this case study since $10 \mathrm{~cm}$ of snow with $10 \%$ wetness would be required to cause a $20-\mathrm{dB}$ loss during the warm period prior to the fall freeze-up. The re-freezing of melt ponds as the primary cause at $\mathrm{C}$ band was dismissed due to the fact that the measurements taken during IAOE'91 were made on a small scale and the melt pond distribution hypothesis depends on large-area averaging. The fourth hypothesis is that moisture on and near the ice surface doesn't allow penetration into the sea ice when the temperatures are warm. When the temperature drops this wet layer will freeze allowing for the penetration of the electromagnetic energy into the sea ice volume. The increase in backscatter during the fall freeze-up could be the result of this enhancement of volume scatter as the temperature drops.

A number of young ice types were investigated during IAOE'91. These included white nilas, dark nilas, and pancake and slush sea ice types. Detection of these ice types are important in the interaction between the sea and the air since they indicate the initial stages of new ice growth and a change in the amount of surface area for heat exchange between the ocean and air. The youngest sea ice types also significantly affect the albedo of the surface as it changes from a sea surface to an ice surface. These measurements indicate that for spaceborne SAR sensors, such as ERS-1 and RADARSAT, to be capable of observing dark nilas ice they must be able to measure $\sigma^{\circ}$ as low as $-30 \mathrm{~dB}$ for $\mathrm{VV}$ polarization and $-34 \mathrm{~dB}$ for $\mathrm{HH}$ polarization. The ERS-1 SAR may be able to observe slightly older sea ice types, such as white nilas and pancake ice, due to the higher backscatter from these ice types. To observe the crosspolarized response of these young ice formations a sensor must be capable of measuring $\sigma^{\circ}$ values as low as $-50 \mathrm{~dB}$. 


\section{Acknowledgments}

The authors would like to thank Dr. Frank Carsey for initiating the project and providing guidance. We would also like to thank Dr. Caren Garrity and Ken Asmus of the Microwave Group, Ottawa River, Canada, for their help during IAOE'91, as well as supplying the snow and meteorological data. Thanks also go to the US Coast Guard and Dr. Leonard Johnson for their support of the experiment. This work was funded by an Office of Naval Research (ONR) doctoral fellowship, as well as ONR grant \#N00014-89J-1456, and NASA grant \#NAGW-1984,D-10847. 


\section{References}

Bredow, J.W. (1989), "A Laboratory Investigation Into Microwave Backscattering from Sea Ice," Ph.D. Dissertation, Department of Electrical and Computer Engineering, University of Kansas.

Carlström, A. (1992), personal communication.

Drinkwater, M.R., and F.D. Carsey (1991), "Observations of the Late-Summer to Fall Sea Ice Transition with the $14.6 \mathrm{GHz}$ SEASAT Scatterometer," IGARSS'91, vol. III, pp. 1597-1600.

Hallikainen, M.T., F.T. Ulaby, and M. Abdelrazik (1986), "Dielectric Properties of Snow in the 3 to $37 \mathrm{GHz}$ Range," IEEE Transactions on Antennas and Propagation, Vol. AP-34, no. 11, pp. 1329-1339.

Hallikainen, M.T. (1992), "Review of the Microwave Dielectric and Extinction Properties of Sea Ice and Snow," IGARSS'92, vol. II, pp. 961-965.

Kong, J.A. (1990), Electromagnetic Wave Theory, New York: Wiley-Interscience.

Skolnik, M.I. (1980), Introduction to Radar Systems, New York: McGraw Hill, pp. 81-91. 


\section{Appendix: Timetable of major events}

11 Aug '91 Sun Ship departs late evening

13 Aug '91 Tue Power-up check of FM-CW system o.k. in lab.

14-15 Aug Wed-Thu Mount and equipment setup on bridge and flying bridge. Reach ice edge on late 14 Aug.

16 Aug. Fri Missed first ice station (CRREL,MWG), IF-RF cables too short, rewired Amphenol connectors.

17 Aug. Sat Missed second ice station(CRREL, MWG) cables replaced and antenna motoring boxes repaired. Radar not working properly.

18 Aug. Sun System brought indoors. Trouble-shooting reveals intermittent problems. Set up step freq. system. missed third ice station (CRREL,MWG)

19 Aug. Mon Missed fourth ice station (CRREL, MWG), repaired loose coax. inside IF box and siliconed all edge connectors. Finished step freq mount and fought software difficulties with step frequency system

20 Aug. Tue Ship stopped for major repair of port shaft. Run-through external delay line tests indoors 
21 Aug. Wed Ship stopped still. Re-mounted FM-CW system. raised mount for $12^{\circ}$ to $70^{\circ}$ capability. Performed angle calibrations looking at brash ice.

22 Aug. Thu Ship still stopped. Rondevous with ODEN. First backscatter measurements of FY(2Y) flow as floated by ship. CRREL station on adjoining flow. Helicopter crashed while returning from visit with ODEN.

23 Aug. Fri Ship stopped. Measurements taken in footprint-laden ice due to on-ice activities of scientists. Fought with step_rad and transit boards all day.

24 Aug. Sat Ship repaired to get underway in morning. Measurements made of MY flow. Caren took snow data and CRREL took ice data aft of ship (not near radar footprint).

25 Aug. Sun Took several transit data sets with old data acquisition system. No ice stations. Amid optimism ship stopped once again in evening with a second port shaft problem

26 Aug. Mon No data taken. Ship stopped with no regard to science on starboard side of ship. Young ice types forming on port side, beginning of all day freeze-up. Some on-ice op's.

27 Aug. Tue Measurements taken of MY flow. CRREL ice data taken on port side also snow data port side. Informed that mission is scrapped.

28 Aug. Wed Transit data with old system. Coincident radiometer data. No ice station. Soviet SAR data recorded at 00:14 GMT 
29 Aug. Thur First (only) complete ice station. Coincident data with MWG and CRREL also roughness measurements by KU and MWG. Some transit data.

30 Aug. Fri Lots of transit data. One station with roughness and some coincident MWG data. CRREL shutting down in anticipation of leaving ice pack. Soviet SAR data recorded at 23:56 GMT.

31 Aug. Sat Station with coincident MWG data.

1 Sept. Sun Two ice stations for buoys. One with coincident MWG data.

2 Sept. Mon Last station and transit data. Roughness data taken. Begin taking down system.

3 Sept. Tue Complete system takedown and packing. Exiting ice pack

4 Sept. Wed No more ice! 